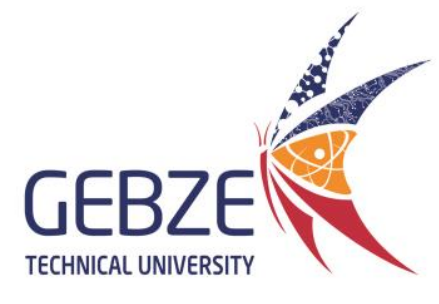

Acta Materialia Turcica

Volume 4, October 2020, Pages 1-39

\title{
Review Paper: Production and Microstructural Phenomena affecting Friction Stir Welding Mechanical Behavior and Applications
}

\author{
O. J. DADA ${ }^{\mathrm{a}, \mathrm{b}}$ \\ ${ }^{a}$ Department for Management of Science and Technology Development, Ton Duc Thang University, Ho \\ Chi Minh City, Vietnam. \\ ${ }^{b}$ Faculty of Applied Sciences, Ton Duc Thang University, Ho Chi Minh City, Vietnam
}

\begin{abstract}
:
Friction stir welding (FSW) is the fastest evolving joining technology and the principal prospective technique for implementing an integral fuselage structure in aircraft manufacturing. The viability of FS welds is dependent upon mechanical properties and production turnovers, which are dependent on welding rates and tool design. Hence this review paper border on the effect of welding parameters, tool designs on microstructure, and mechanical behavior of friction stir welds. The microstructure and micro-hardness which were influenced by the welding rates determined static properties, failure locations, and residual stress minima and maxima. The study reviews the nature and distribution of material flow, grain structure, and precipitates in the aluminum FS welds and their effect on mechanical properties. Advances in the industrial application of Friction Stir Welds and further prospects are critical to this review work.
\end{abstract}

Keywords: Friction Stir Welding; Microstructure; Fracture Mechanism; Mechanical Behavior; Damage Tolerance.

DOI:

\section{INTRODUCTION}

Friction Stir Welding (FSW) is a relatively new process developed by The Welding Institute (TWI-TM, Cambridge, UK) in 1991 [1], which has proved to be a much more viable joining process for all aluminum alloys than earlier techniques, such as metal inert gas (MIG) [2], tungsten inert gas (TIG) [3], laser welding [4,5], resistance welding [6], bolting and riveting [7]. As illustrated in Figures 1-3, a non-consumable rotating cylindrical tool, consisting of a shoulder and profiled pin emerging from it, is plunged into the abutting edges of the two plates to be joined, until a substantial portion of the shoulder is in intimate contact with the surface of the workpiece. Thereafter, the tool traverses the joint as it rotates, inducing heat high enough to locally plasticize and move the material to its rear $[1,8,9]$. Large shearing forces are involved and the temperature of the material is raised to approximately $80 \%$ of the melting point. To make a full penetration weld, the tool is usually designed so that the bottom of the pin is near the bottom surface of the work piece when the shoulder makes contact with the top surface. In addition to providing supplementary frictional heating, the shoulder prevents the expulsion of softened material and consolidates it in a way similar to forging. Transfer of heat is aided by plastic flow of the material close to the rotating tool at high strain rate. Heat and mass transfer depends on material properties and welding variables [10]. 


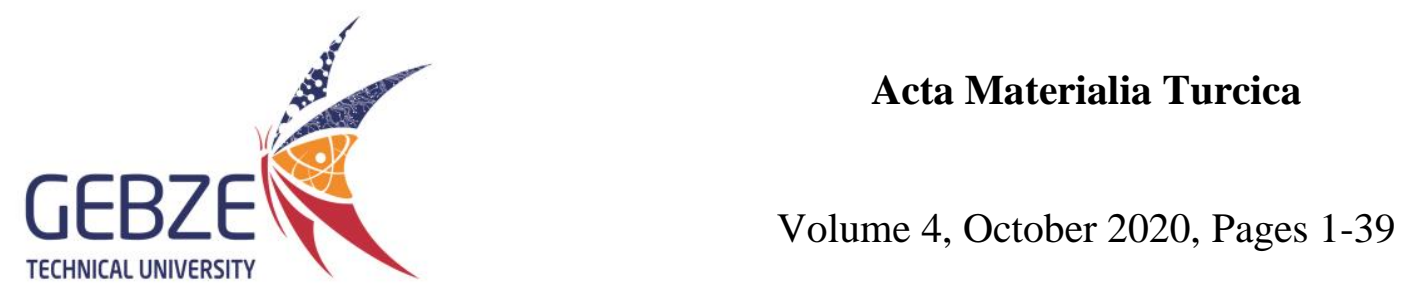

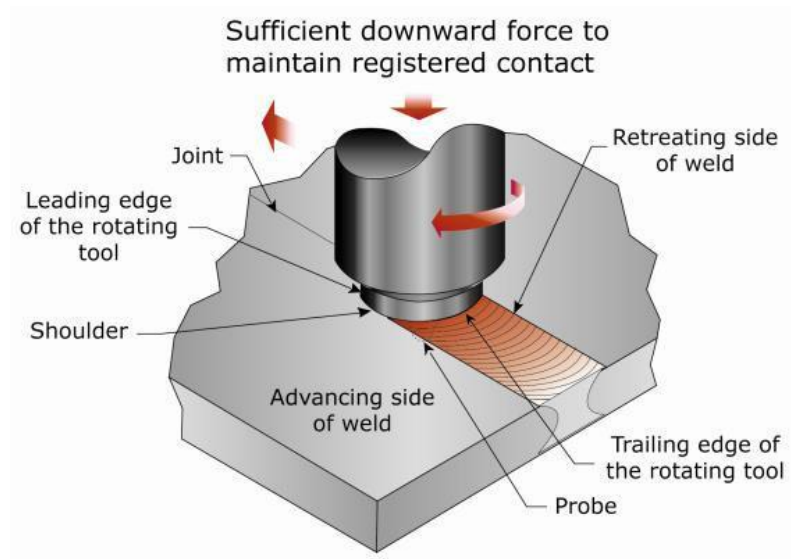

Figure 1. Schematic diagram of the FSW process [11].

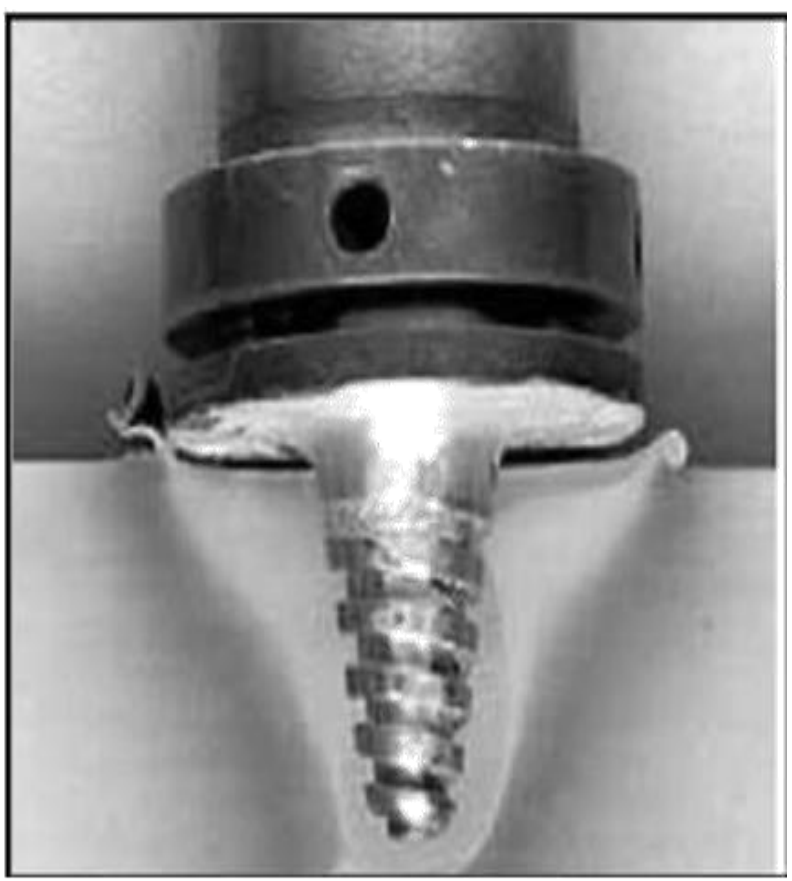

Figure 2. FSW tool in action [12].

\section{Stage 1: Tool Rotation \\ Stage 2: Plunge}
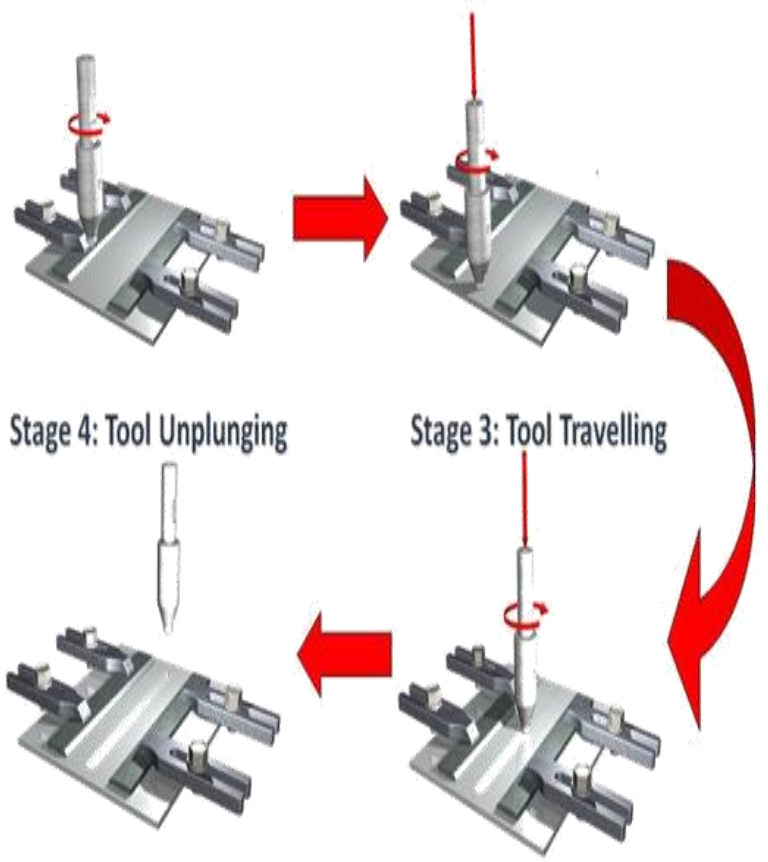

Figure 3. FSW process.

The weld microstructure is usually divided into four zones, namely (Figure 4 [13]):

- Parent material zone which is unaffected in any way. This zone is the same as the workpiece material in terms of microstructure and mechanical properties [13].

- Heat affected zone (HAZ), which is typical in all welds; the material has undergone some thermal cycle but no deformation and has a different microstructure [13];

- Thermo-mechanically affected zone (TMAZ) located between the weld nugget and HAZ. It has undergone some plastic strain without recrystallization. Visible elongation and rotation of the parent material grain structure has occurred in this zone during welding $[13,14]$;

- Weld nugget, which is also known as the stir zone. It has undergone mechanical stirring, resulting in severe plastic deformation, continuous dynamic recrystallization followed by static growth influenced by frictional heat generated by the tool in the material workpiece $[1,15,16]$. It is typified by an onion ring (banded) structure which contains fine 


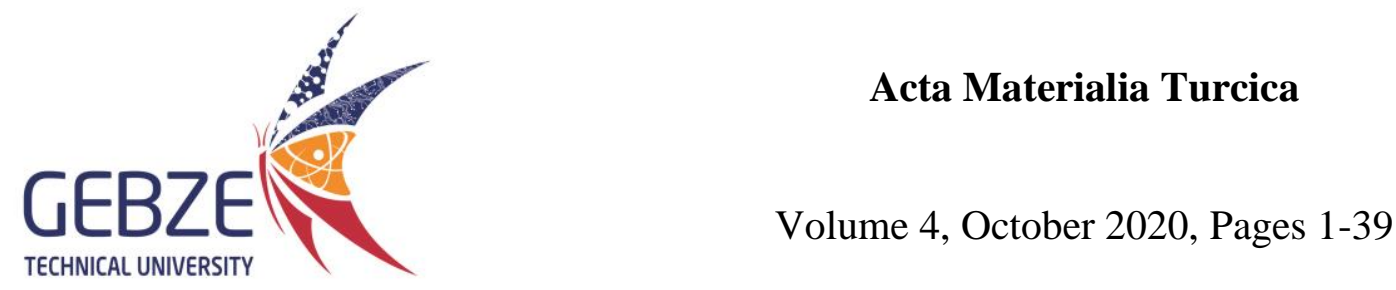

equated grains with high dislocation density and high angle grain boundaries [1-19]. The cross-section of this zone has been reported by some to be elliptical $[20,21$,$] while others have observed a widened weld$ zone near the surface, from frictional heating by the tool shoulder [10,11]. Overall, the shape of this zone depends on the welding parameters and the thermal conductivity of the base material.

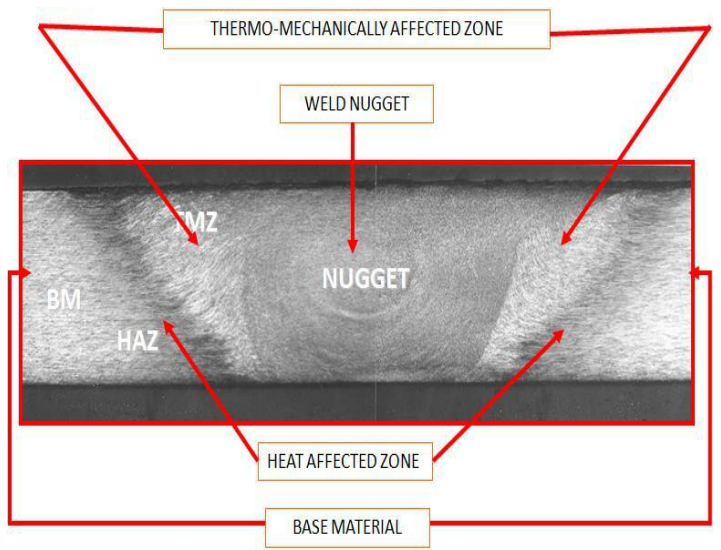

Figure 4. Microstructural Zones in FSW [22].

Of several factors that influence mechanical behavior, microstructure and defect formation in FSW, tool transverse and rotational speed and the condition of the work piece are known to be most significant [1]. FSW has gained more attention from the transport industry, especially in aerospace. Aerospace engineers have identified FSW as one of the most viable alternatives to present joining methods of bolting and riveting. Typically, sheets and plates with a maximum thickness of $100 \mathrm{~mm}$ of 2XXX, 5XXX, 6XXX and 7XXX series aluminum alloys are being welded, and large efforts have been made to understand the in-service behavior of these systems [8].

Friction stir welding results in a fine-grained microstructure, which is responsible for the excellent mechanical properties: fatigue resistance [23], enhanced formability [24] and exceptional super plasticity of the joint [25], and reduced residual stresses [1]. It has been proved to be one of the most effective welding processes to retain strength and toughness in ultra-fine grained aluminum alloys [15]. Alloys that are difficult to fusion weld are wieldable with FSW (Figure 5). It is energyefficient and environmentally friendly, since no harmful emissions are created, and cost-effective, in that it consumes no cover gas or flux, compared to the conventional welding methods. High strength aluminum aerospace alloys which are classified as difficult to fusion weld can be stir welded with minor strength loss $[9,15,26]$. However, the traditional FSW process is limited by factors such as the necessity of a backing plate and stable work fixture, impossibility of welding by material addition, presence of a "keyhole" at the end of the weld, need for material flow models and tools for high-temperature materials, and the necessary post-welding machining $[1,27]$. Keyhole is a depression created in the work piece when the FSW tool is retracted, creating local weakness and an extra step to be filled during manufacturing [28]. Defects such as excess flash, lack of fill under the tool shoulder, internal porosity, and lack of penetration could result if welding is not carried under appropriate tool design and welding conditions [29,30]. 


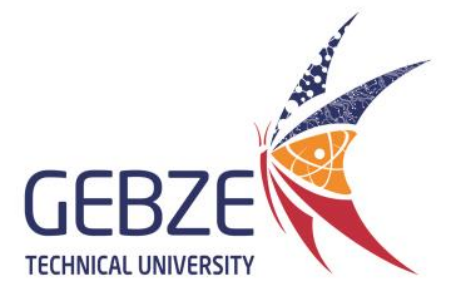

Acta Materialia Turcica

Volume 4, October 2020, Pages 1-39

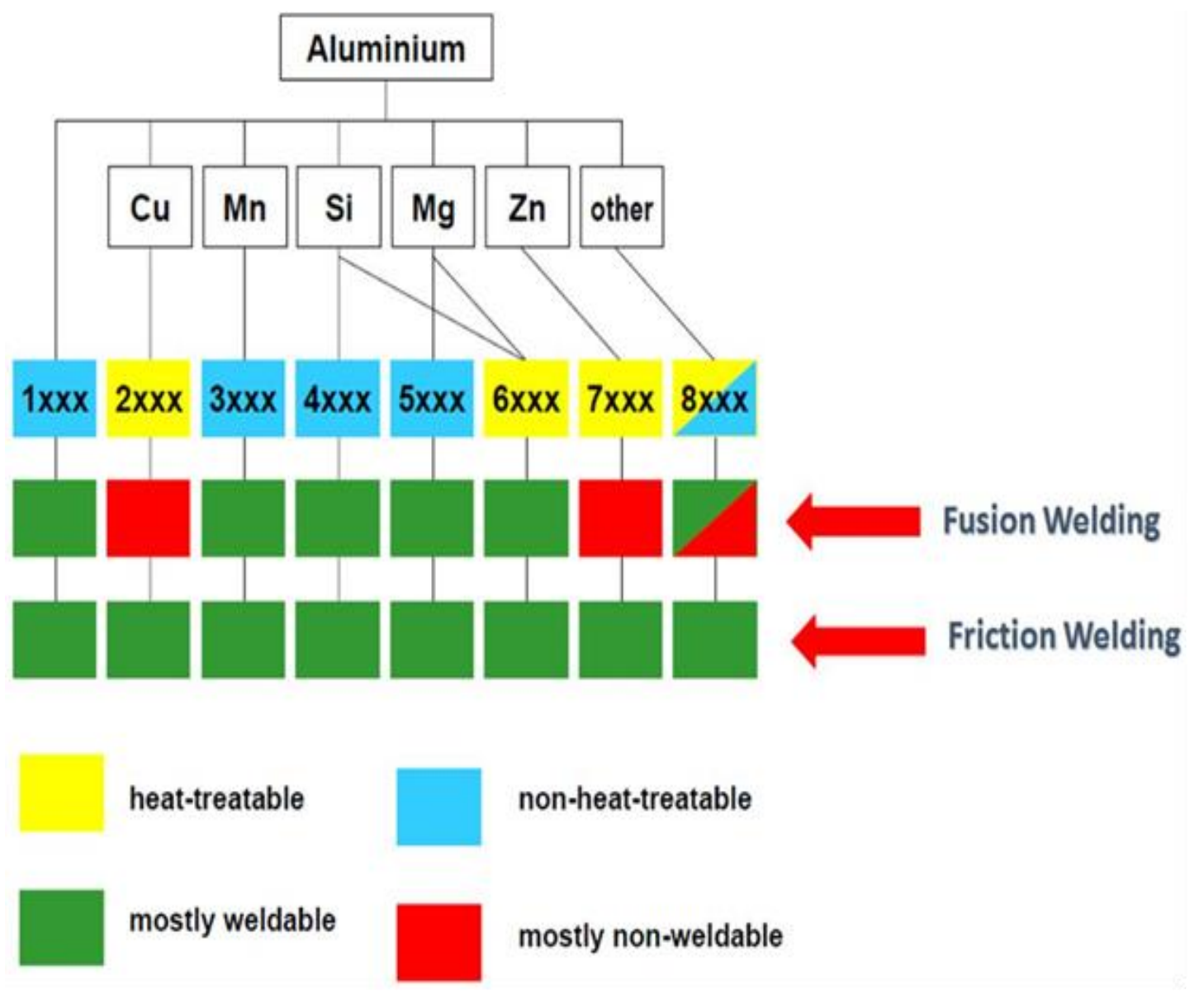

Figure 5. Capability of FSW, TWI ${ }^{\circledR}[13]$.

\section{JUSTIFICATION}

The principal prospective application of FSW in aerospace is in the manufacture of integral fuselage structure and wing fairings. This entails butt-joining of rolled sheets and T-joining of stringers with skin sheets and clips $[8,9,32]$. This is proposed to eliminate the problems of excess weight, high cost, widespread fatigue damage and energy consumption associated with the traditional fastening method of riveting, while also optimizing production time, corrosion resistance, damage resistance, reliability, maintainability, service life and safety [7-9,32-35,].

Also, new aerospace alloys (AA6056, AA6013, AA6082, Al-Mg-Sc and Al-Mg-Li) are being studied while extensively used high strength alloys (2XXX Al-Cu and $7 \mathrm{XXX} \mathrm{Al}-\mathrm{Zn}$ series) are being tested for optimized usage under simulated aerospace environments [6,32-34]. While many research papers have appeared on FSW of structural aerospace aluminum alloys, it is still challenging for aerospace engineers to design and implement FSW in practice. The effects of carrying out FSW on coated panels and the presence of standard FSW root flaws are major drawbacks. Before paints are applied on airframes, corrosion protection is given by a chromium-based chemically-bonded conversion coating known as "Alodine" or a metallurgically bonded alumina $\left(\mathrm{Al}_{2} \mathrm{O}_{3}\right)$ layer formed by the electrolytic process of "anodizing". Both of these methods are known to have a deleterious impact on mechanical properties, especially fatigue resistance. Theoretically, it is maybe correct to assume FSW of the anodized plate will have lower 
soundness, because of the resulting inclusion of oxides and the creation of surface cracks in the base material. However, the consequences of avoiding oxides by removing the oxide layer before welding and replacing it with a post-weld electro less alodine coating must be understood in terms of fatigue and fracture characteristics [36,37]. Understanding the effect of the oxide layer on crack initiation and propagation is a priority. Root flaws along the line of penetration, which are difficult to detect with conventional NDT methods, also act as crack initiation points, thereby undermining the integrity of the weld $[27,30,38,39]$. They result from the unreformed region between the bottom of the tool and the bottom surface of the plate. Research on the effects of all the above factors on the performance of innovative joints from specialized root flaw avoiding tools is needed. The elimination or reduction of root flaws has been shown to lead to an increase in UTS, ductility, and fatigue life $[27,38,39]$.

The absence of uniform guidelines, process specifications, and a thorough understanding of thermal input via frictional heating and material flow mechanics are also systemic setbacks affecting the industrial application of FSW. Prediction of the resultant microstructure and defect-free nuggets for a set of process parameters and tool configuration is necessary, and can only be achieved with research [1,18,40-42]. Hence, solutions-driven research activities in line with these motivations are expected to contribute to the knowledge base, with the view of enhancing its adoption by the aerospace industry.

Airframe coatings on the fracture and failure characteristics of the joint. Innovative FSW joints will be made using the Delta- $\mathrm{N}$ tool, a new tool that features a stationary shoulder and rotating pin developed with a simple but robust design to minimize distortion.

The following are the objectives:

- To compare the mechanical performance of innovative FSW joints to established standard FSW joints, and derive the effects of airframe oxide coatings on fracture behaviour.

- To macroscopically establish the soundness of the joints obtained using the innovative "Delta-N" tool by examining the surface of the welds for defects (if any) and other notable salient features.

- To conduct microstructural analysis and provide explanations for mechanical test results.

\section{DAMAGE TOLERANCE CRITERIA IN AEROSPACE \\ MANUFACTURING AND} STRUCTURES

Damage tolerance is the ability of a structure to sustain defects safely until the repair is carried out. Damage tolerance design is based on fracture mechanics and crack propagation evaluations which provide data and inspection procedures throughout the lifetime of the aircraft [43]. FSW has been widely used in the manufacturing of aerospace structures, such as fuselage, wings, and sheets [6]. Civil aircraft are normally designed for up to 90,000 flights and an approximate lifespan of up to 25 aviation years. Aircraft for the future will be designed for almost the same lifecycle, but with a higher fatigue endurance, higher damage tolerance, and higher corrosion resistance, to minimize maintenance cost and to comply with requirements of the operator and the enhanced airworthiness regulations [44]. The requirements of damage tolerance evaluation are [44]:

-Widespread fatigue damage assessment,

-Identification of possible damaged locations and extent of damage,

-Damage tolerance analysis and test, and

-Determination of inspection threshold and intervals.

During the design of airframes, full-scale fatigue testing is carried out on each element of the completely safe structure. Fatigue design criteria to be met are static strength, residual strength, crack growth, sonic fracture, and the two-bay-crack criterion (the ability to withstand a static load in the presence of a crack in the fuselage skin within two frame or stringer bays [45]). In a bid to fulfill the two-bay-crack criterion, the following precautions are imposed to mitigate consequences in terms of weight increase [44]:

-Selection of skin materials with high residual strength,

-Selection of frame materials with high static strength, -Limitation of allowable frame pitch, and

-Adaptation of stress level to the two-bay-crack criterion.

Aircraft wings, empennage (tail assembly), and fuselages are all critical areas in terms of fatigue considerations and repair. The introduction of new production techniques, such as friction stir welding, laser 
beam welding, and extrusion in line with these criteria require more sophisticated NDT methods, and aluminum alloy production and development. Minimizing maintenance cost, optimization of material, production cost, and weight are issues influencing decisions on airframe manufacturing for commercial purposes [33,44].

During the aircraft design phase, external loads are resolved into structural airframe loads. Finite element analysis is usually employed, taking into consideration the geometry and structural stiffness of the major components. Success in determining the nature and magnitude of component design loads is a major prerequisite for the successful design and safe operation of any aircraft. Figure 6 shows the different loads associated with aero structures

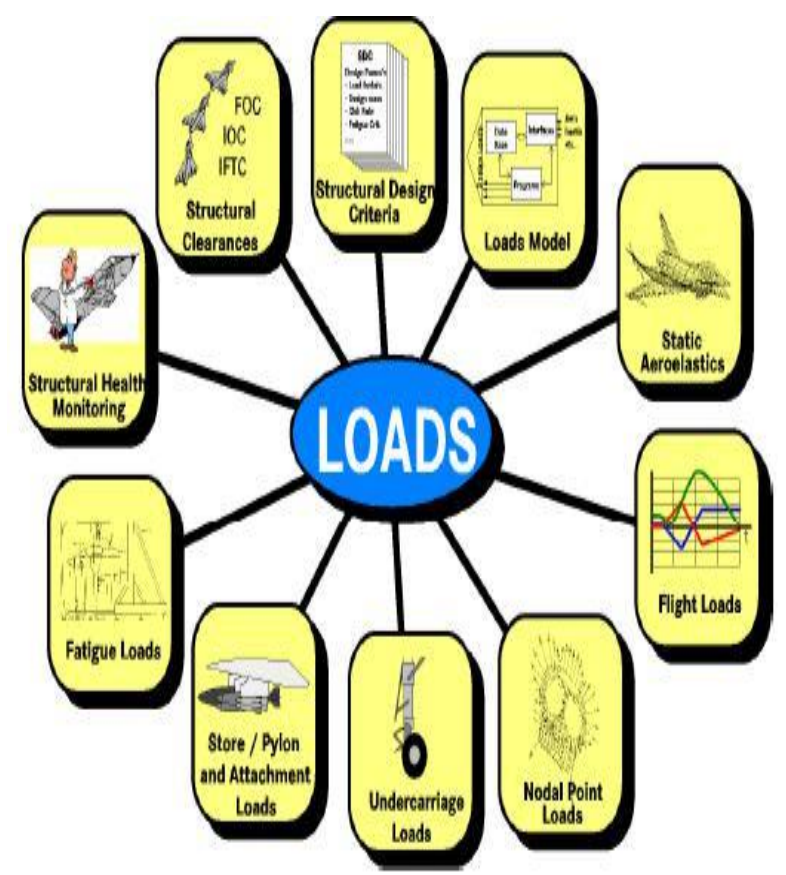

Figure 6. Sources of aircraft loads [46].

The operational readiness of an aircraft is largely dependent on the condition of the airframe's structure in terms of its ability to retain structural integrity in the presence of the stresses resulting from the various loads. The detailed design of wings and fuselage structures is influenced by the "initial design loads" of the airframe. Maintenance operations and upgrading of components of an aircraft usually have influences on the load acting on the airframe, especially in ageing aircraft. Fatigue load causes are derived from quasi-static (flight loads combined with local and internal loads) and dynamic (acoustic noise and dynamic buffets) load conditions if the frequency of these loads is high enough during assumed usage conditions [46]. Flight loads result from symmetric maneuvers, asymmetric maneuvers, the deep and flat spin of the aircraft, as well as gust loads resulting from wind [46]. Local and internal loads are generated by the engines and aerodynamic systems. Dynamic buffets, which are felt on the wings and empennage, are from aerodynamic fluctuations.

Aircraft structures are designed to withstand maximum static loads, as well as repeated loads in addition to manufacturing defects and in-service damage, without detrimental degradation of the structures that may eventually lead to catastrophic damage [46]. Welding reduces the residual stress, fracture, and damage tolerance properties of aerospace material, depending on the alloy type, temper condition, and welding parameters. The extra material and design compensations in the form of structural reinforcements, which could have weight implications, could be needed to mitigate these negative effects. As a result, welding with limited local reinforcement is mainly applied to fuselage areas (side and lower shells) with predominantly static loads [7].

\section{DESCRIPTION OF ALUMINIUM ALLOYS FOR AERONAUTICAL STRUCTURES}

In the aerospace industry, aluminium is an established material. It has retained its leading-edge despite stiff competition from polymer-based composites and hybrid materials in terms of cost, weight, and performance [7,35]. By weight percentage, the Airbus 380 presently comprises $61 \%$ aluminium, $22 \%$ composite materials, and $3 \%$ fibre metal laminates (GLARE®) [7]. This is because aluminium alloys possess high specific strength, high toughness, ease of manufacture, long term performance, recyclability, weldability, and no low-temperature brittle fracture [35] because they are FCC based.

Alloy 2024 is an Al-Cu-Mg alloy with high yield strength and good fracture toughness. It is heat treatable, possessing a combination of high damage tolerance and resistance to crack propagation; good fatigue resistance, especially in thick plate forms; good machinability; good workability and surface finish, but only fair corrosion resistance [47]. According to Mathers [48] and Hatch [49], the bulk of the increased strength is caused by the formation of copper aluminide $\mathrm{CuAl}_{2}$ precipitates. On solution strengthening, $2024 \mathrm{Al}$ will naturally age at room 


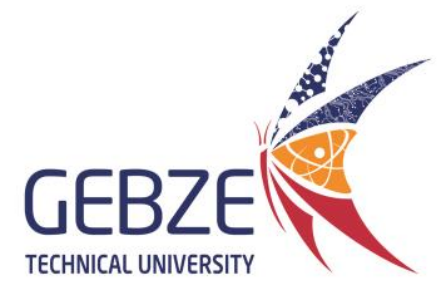

Acta Materialia Turcica

Volume 4, October 2020, Pages 1-39

temperature and achieve stable properties after four days. The weldability of this alloy with conventional welding processes, such as gas metal arc welding and gas tungsten arc welding, is limited. It is more sensitive to hot cracking, hence joint design and fixtures are usually balanced to limit the strain on the joint when cooling during conventional welding processes. Its yield strength and tensile strengths are $424 \mathrm{MPa}$ and $472 \mathrm{MPa}$ respectively $[1,14]$. The 2024-T3 is susceptible to exfoliation, intergranular corrosion, stress corrosion cracking, and pitting [35]. The T351 temper condition results from water quench after solution treatment at $493^{\circ} \mathrm{C}$, followed by a few percent plastic deformations and several months of natural ageing [14].

Alloy 6056-T4 is similar to AA6013-T3. It has similar mechanical properties to AA2024 and it was developed to replace it. AA6056-T4 has improved weldability with good strength and corrosion resistance and it is formed by the addition of Si-Mg-Zn-Cu-Mn. It has precipitates such as the oval-shaped quaternary phase $\mathrm{Q}-\mathrm{Al}_{5} \mathrm{Cu}_{2} \mathrm{Mg}_{8} \mathrm{Si}_{6}-\lambda$ found at grain boundaries and the plate-shaped $\mathrm{Mg}_{2} \mathrm{Si}-\beta$ [50].

Alloy 6013 is an Al-Mg-Si-Cu alloy and a medium strength aerospace alloy that provides high formability, machinability, improved corrosion resistance, lower density, and low sensitivity to high temperature. It has yield strengths $12 \%$ higher than Alclad 2024-T3, virtual immunity to exfoliation and stress corrosion cracking, and lower price $[9,32,47]$. It is weldable by gas tungsten arcwelding (GTA), metal gas arc-welding (MGA), and resistance welding. In general, $6 \mathrm{XXX}$ aluminium alloys naturally age more slowly than $2024 \mathrm{Al}$, hence mechanical properties do not change dramatically with time. Its yield strength and tensile strength are in 226 and $351 \mathrm{MPa}$ T4 temper and 346 and $396 \mathrm{MPa}$ T6 temper.

AA6082-T6 is a structural alloy of medium strength and excellent corrosion resistance. The high amount of manganese in this alloy controls the grain structure, which is the cause for the high strength of this alloy in the 6XXX series. It has been applied for the replacement of 6061 in many applications. It is highly weldable by fusion techniques such as brazing and soldering [51].

The 5XXX aluminium alloys are non-heat treatable Al-Mg alloys based are single-phase binary alloys with good strengths and toughness. They possess high weldability, machinability, and corrosion resistance. They are choice materials for pressure vessels of spaceships and aircraft [52]. They are also applied in automobile structures to reduce weight, thereby reducing fuel consumption and emissions, with low maintenance and cost, without negatively impacting on performance, comfort, and safety [53]. The AA5083 is an Al-Mg-Mn based structural alloy with mechanical properties such as high strength, high formability, and excellent corrosion resistance in seawater, as a result of the presence of magnesium [31]. The presence of magnesium (from 1$5.5 \%$ ) also promotes solid solution strengthening and increases the rate of work-hardening. Manganese increases the recrystallization temperature and promotes formation of strengthening precipitates. However, increasing magnesium content can result in porosity, cavities, and hot cracking in traditional welding processes like arc-welding and metal inert gas welding. Work hardening and grain refining are strengthening mechanisms for this alloy, being a solid solution strengthened material [54]. The H111 condition is obtained by strain hardening for specific applications in shipbuilding (warships, littoral surface crafts, and fast passenger ships) [55], automobiles, and fuel tanks [56,57]. 
Table 1. The typical chemical composition of aeronautical alloys (wt $\%)$ [9,47,52,58-60].

\begin{tabular}{|c|c|c|c|c|c|c|c|c|c|c|}
\hline & \multicolumn{10}{|c|}{ Composition (wt\%) } \\
\hline & $\mathrm{Si}$ & $\mathrm{Fe}$ & $C u$ & $M n$ & $M g$ & $\mathrm{Cr}$ & $Z n$ & $\mathrm{Ti}$ & Other & $A l$ \\
\hline AA2024 & 0.5 & 0.5 & $3.8-4.9$ & $0.3-0.9$ & $1.2-1.8$ & 0.1 & 0.25 & 0.15 & 0.05 & Remainder \\
\hline AA6013 & $0.6-1.0$ & 0.6 & $0.6-1.1$ & $0.2-0.8$ & $0.8-1.2$ & 0.1 & 0.25 & 0.1 & 0.05 & Remainder \\
\hline AA6056 & 0.87 & 0.07 & 0.67 & 0.62 & 0.71 & - & 0.18 & - & - & Remainder \\
\hline AA5083 & 0.12 & 0.33 & 0.03 & 0.51 & 4.39 & 0.08 & 0.01 & 0.02 & 0.05 & Remainder \\
\hline AA6082 & $0.7-1.3$ & $<0.5$ & $<0.1$ & $0.4-1.2$ & $0.6-1.2$ & $<0.25$ & $<0.2$ & $<0.1$ & 0.05 & Remainder \\
\hline
\end{tabular}

\section{PARAMETERS CONTROLLING ALUMINUM FSW}

Tool rotational and welding speeds play a major role in determining weld quality [6,61-64]. Increased rotational speed, up to an optimum value, increase tensile strength [63]. This optimum value exists because the coefficient of friction that generates the heat gradually reduces as the rotational speed increases [64]. The coefficient of friction is determined by the hardness of the material. Hence, the harder the material, the greater the heat generation [65], whereas it decreases with an increase in transverse speed, and increases with vertical pressure [10]. This is because of heat input increases, resulting in higher frictional heat and more intense stirring of the material. Beyond the optimum, higher temperatures and slower cooling rates result in the stirred zone having micro-voids. Lower welding speed at higher rotational speed causes grain coarsening, reduced dislocation density, and sub-boundaries, impacting negatively on tensile strength. If lower welding speed and higher rotational speed are combined with small pin diameter and higher axial force, turbulent material flow occurs [65]. Too high welding speed decreases the heat input because the time of frictional interaction of tool with the workpiece per unit length of the weld is reduced, reducing the tensile strength of the joint. A similar case was reported by Yan et al.[66], with an increase in hardness for an increase in rotational speed from 150 to $300 \mathrm{rpm}$, remaining constant at $135 \mathrm{KHN}$ from 300 to $800 \mathrm{rpm}$ for FSW of 2524 aerospace aluminium alloy. Nugget hardness increased with rotational speed and grain size giving an inverse HallPetch effect [66]. However, HAZ minimum hardness values were unaffected by rotational speed increase [66].

Heat generation in FSW is carried out by the shoulder and the pin $[6,10]$. More heat is generated at the crown surface than at the bottom. The reason is that the contact of the shoulder with the material surface generates additional heat at the top, while at the bottom, more heat is conducted away by the root surface adjacent to the backing bar. It is expected that there will be a decreasing temperature gradient from top to bottom of the workpiece material, depending on material thickness and other contributing factors. Hardness variation through the material thickness, greater at the surface and lower at the root, has been recorded only within and around the weld nugget because of the high thermal conductivity of aluminium.

In summary, the following principal parameters are used to govern FSW $[1,6,10]$ : 1. Welding speed, 2. Tool rotational speed, 3. Vertical pressure on the tool, [4]. The tool tilt angle, and 5. Tool design. These variables determine the heat generation rate, temperature field, cooling rate, $\mathrm{x}$-direction force, torque, and welding power [10]. Welding tool erosion and breakage may result from excessive $\mathrm{x}$-direction force. High vertical pressure can lead to overheating, while low pressure may induce voids in the weld nugget. Tilting the tools $\left(1-3^{\circ} \mathrm{C}\right)$ towards the trailing direction helps to move the stirred material effectively from the front to the back of the pin [67].

\section{FORCE GENERATION İN FSW}


FSW results in the generation of forces on the tool in $\mathrm{x}, \mathrm{y}$, and $\mathrm{z}$ directions, as shown in Figure 7 . The force along the tool axis, $F_{z}$, is also known as the normal or downward force. It is the forces that maintain the tool at or below the surface of the welded joints. Too low downward force usually results in the formation of weld defects such as pinholes and tunnels. The force acting in the direction of the tool translation along the joint, Fx, is known as the transverse force. It decreases as the temperature of the material increases since it is the force required to overcome the resistance of the material to the translation of the tool. Lateral force, Fy, is that which is perpendicular to the direction of tool translation and it is positioned towards the advancing side.

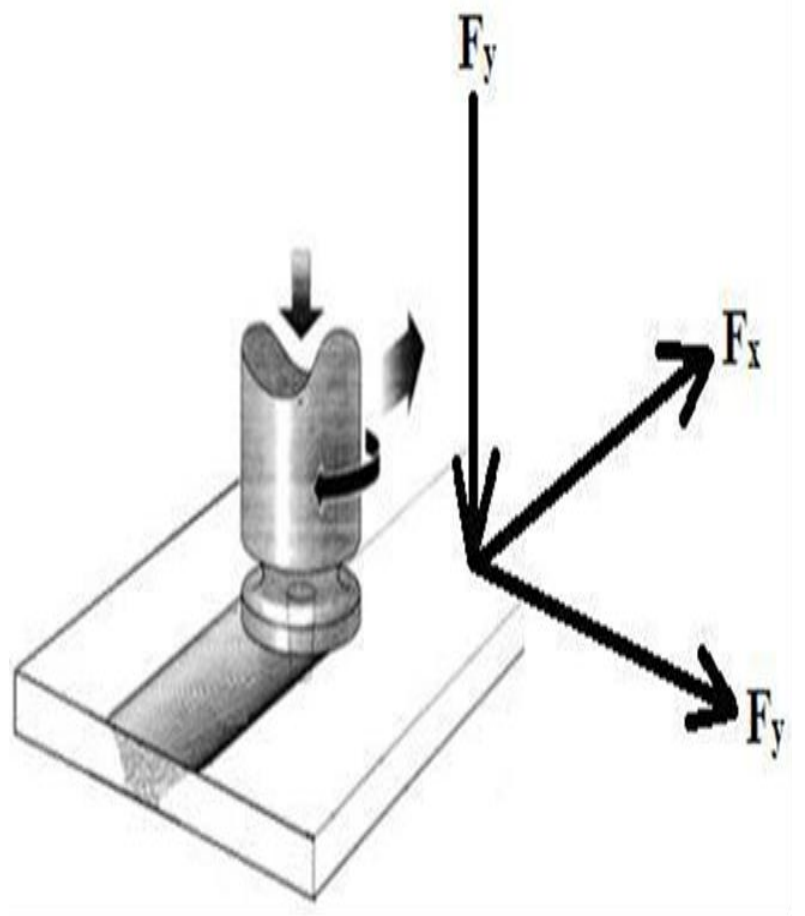

Figure 7. Schematic forces acting on the tool during friction stir welding [68].

Excessive welding forces may result in undesirable wear, tear, or fracture of the tool. Combination of welding parameters that yields the lowest tool forces may result in welds with defects or low productivity. Therefore, it is common for FSW experts to seek optimal parameters that yield the best joint properties, the highest productivity, and lowest tool forces.
At the initial plunging of the tool into the material during the dwelling stage in FSW, the downward and lateral force increases greatly and become very high, and may force apart the plates if clamping is not properly done [1]. This is because the temperature of the material is still very low and the yield strength is high. After the dwelling stage, the material softens and the downward force reduces.

The position or penetration of the tool into the material while welding is sustained by controlling the penetration depth (position-control FSW) or controlling the applied normal force, Fz (force-control FSW) [68]. The typical evolution of the vertical force from beginning to the unplugging stage of welding of dissimilar AA2024AA6082 done by Cavaliere et al. [68] is given in Figure 8. The two alloys were interchanged on advancing and retreating sides at two different welding speeds. The relationship between temperature and downward force was illustrated by Trimble et al. [69] in Figure 9. Two peaks were recorded, the first peak representing the force on the pin during tool penetration and the second is due to plunge depth at which the shoulder presses the workpiece.

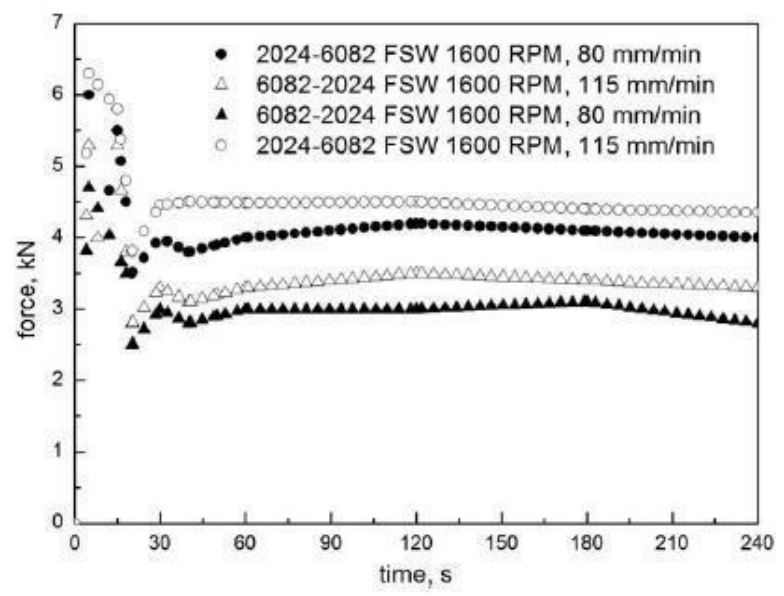

Figure 8. Vertical forces acting on the tool at different welding conditions [68]. 


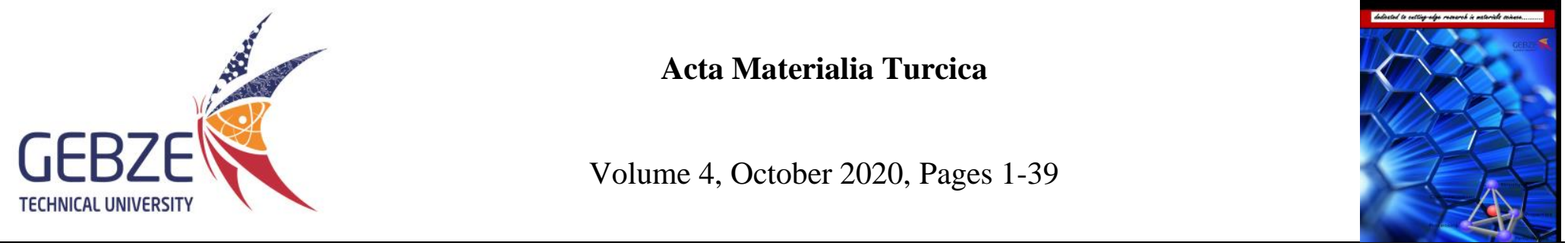

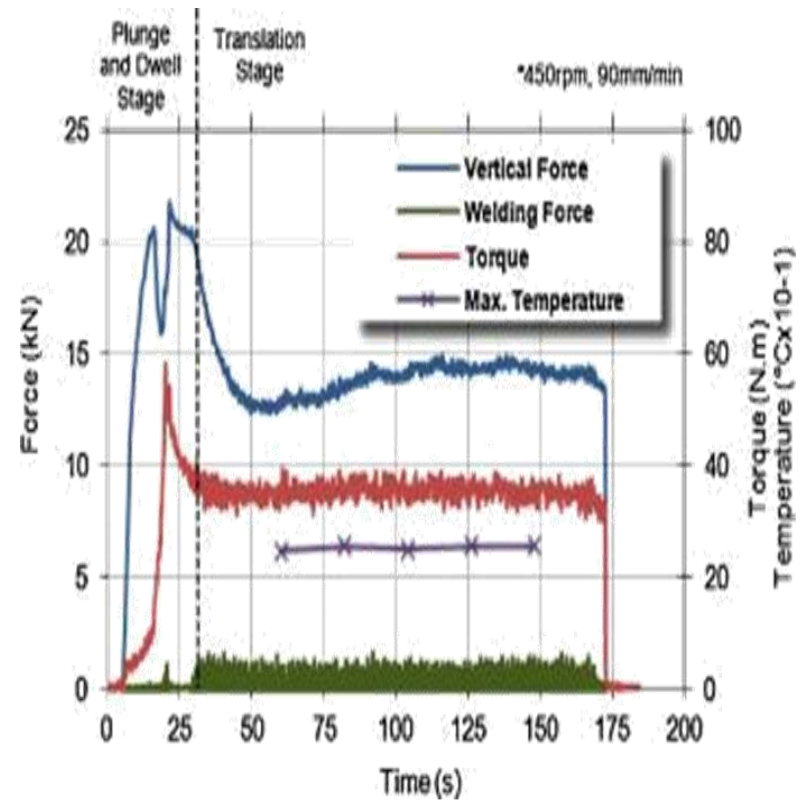

Figure 9. Downward force profile and temperature [69].

\section{MECHANICAL PROPERTIES OF FSW ALUMINIUM ALLOYS}

The good properties of FSW are due to controlled and response variables, as well as external boundary conditions. The functional behaviour of FS welds is determined by the weld strength, metallurgical behaviour, surface roughness, weld hardness, and microhardness [67]. The mechanical integrity of an FSW joint is a product of complex thermo-mechanical interactions resulting from heating and cooling rates, plastic deformation and material flow, and dynamic recrystallization [10]. When the load is transversely applied across the FS welded sheet, strain localization occurs in the low strength region, since each of the zones possesses unique mechanical properties [14]. This has led to the failure of FSW samples at lower levels of strains (i.e. low strain-to-failure) when compared to unwelded parent materials [70]. Under static loading, failure has mostly been reported to have occurred in the HAZ [1 $10,16,17,21,71,72]$. The direction of tool rotation, which accounts for asymmetry in heat transfer and material flow, has also led to differences in the mechanical properties on the advancing and retreating sides of the FS weld [10]. The hardness data across the weld is usually taken as the initial evaluation of the mechanical properties.

\subsection{XXX ALUMINIUM ALLOYS}

With good welding practice, hardness values within the weld nugget range between 100 and $140 \mathrm{HV}$, decreasing from crown to root as reported by Mishra et al. [1], Barcellona et al. [18], Genevous et al.[14] and Jones et al.[73]. Highly elongated and deformed grains in the TMAZ show a sharp decrease in hardness until it reaches a minimum near the HAZ. The HAZ, which possesses a microstructure which is similar to the parent material, has a low hardness which increases until it reaches values of that of the parent material. In $2024 \mathrm{Al}$, yield strength, which is often related to hardness, as well as fracture location, should correlate with the lowest hardness location in the "W" hardness curve. Biallas et al. [74], Von Strombeck et al. [75] and Magnusson et al. [76] found the highest yield strength was obtained for the combination of higher tool rotation rate and travel speed. The reprecipitation of hardening particles when "critical cooling rates" were exceeded was responsible for high yield and tensile strength recorded at higher transverse speed. About $66-72 \%$ and $93-100 \%$ of the yield strength and $82-87 \%$ and $90-98 \%$ of the tensile strength of the base materials were recorded for $4-5 \mathrm{~mm}$ and $1.6-2 \mathrm{~mm}$ thick sheets respectively. FSW was carried out by Magnusson et al. [76] at half the transverse and rotational speeds used by Biallas et al. [74], hence it may be concluded that sheet thickness and tool design are more important than FSW parameters about cooling rate, heat input, and resultant yield strength. However, results from welded $3 \mathrm{~mm}$ samples by Srivatsan et al. [70] showed how the direction of heat flow from the nugget can influence tensile properties. Samples, where the FSW setup was done to allow heat to dissipate rapidly through the backing plate, had $92 \%$ of the tensile strength of the base material, while for the samples where heat passed through the edges of the plates the tensile strength was $84 \%$. Strain-to-failure of $25 \%$ and $60 \%$ for the base material was reported for the latter and former respectively. Yield strengths ( $72 \%$ of the base material) were similar to those reported by Biallas et al. [74] and cross-sectional ductility was $60 \%$ that of the base material.

With regard to transverse strain, the tensile gauge length is obviously complex because the different microstructural zones exhibit different strengths. The transverse strain of the FSW recorded in Lohwasser [77], Magnusson and Kallman [76], von Strombeck et al. [75], and Biallas et al[74] was an average of 8.5\% (5.1-16.3\%), 
which is lower than that of the base metal which ranges from $15-21 \%$.

The fatigue strength evaluated at $2 \times 105$ cycles recorded by Bussu et al. [78] for surface skimmed FSW $2044 \mathrm{Al}$ for $1.6 \mathrm{~mm}$ and 4-6 mm was unchanged and slightly lower than that of the base material. A complete comparison between the base material and FSW showed degradation in fatigue strength due to FSW (Figure 10) The loss in fatigue strength was greater for tests performed in transverse orientation than in longitudinal, as shown in Figure 11.

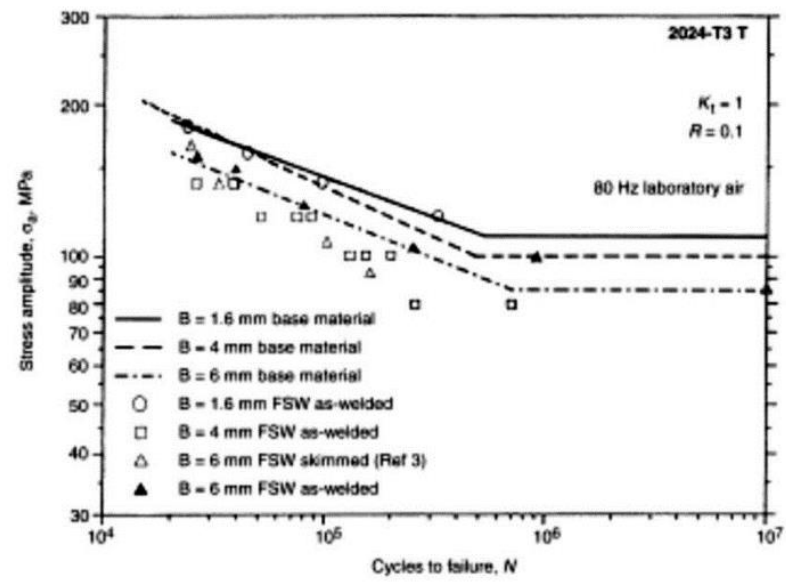

Figure 10. Stress-number of cycles $(\mathrm{S}-\mathrm{N})$ curve of $6 \mathrm{~mm}$ as-welded butt joints of 2024-T3 compared to the S-N curves of thinner as-welded joints, skimmed joints, and base-metal curves. FSW, friction stir welded [79].

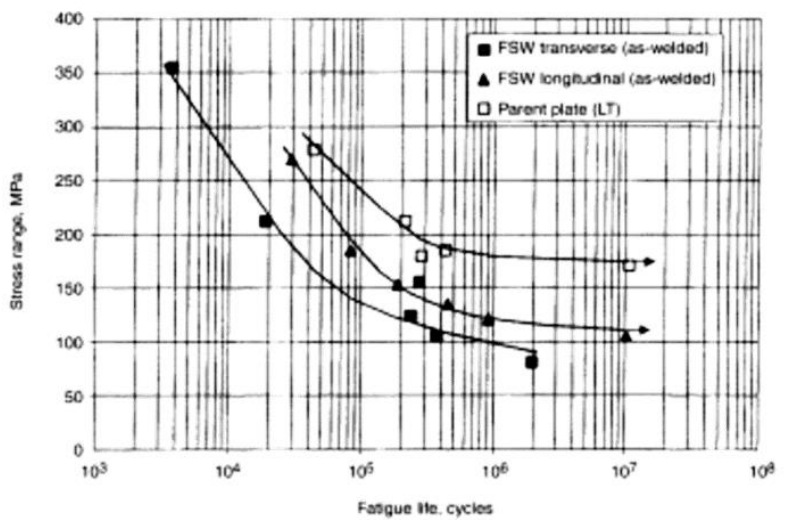

Figure 11. Stress-number of cycles $(\mathrm{S}-\mathrm{N})$ curves $(\mathrm{R}=$ 0.1 ) of parent plate and friction stir welded joints in the as-welded condition [78].

Corresponding Author E-mail: oluwaseunjohndada@tdtu.edu.vn
Fatigue crack propagation results, using surface crack tension and compact specimens, with the cracks oriented in the weld direction, were reported in Christner et al. [80] and Bussu et al. [78] and Mishra et al. 1. In the first, crack growth rates $(\mathrm{da} / \mathrm{dN})$ in the weld nugget were slightly faster than in the base material, chiefly at lower values of stress-intensity range $(\Delta \mathrm{K})$. The high crack growth rate has been attributed to the fine grain microstructure in the weld nugget. Conversely, in Bussu et al. [78], the lowest threshold $\mathrm{K}$ values and the highest growth rates were exhibited by cracks propagating at $28 \mathrm{~mm}$ from the plate joint line. At low $\mathrm{K}$, cracks in the weld nugget grew faster than those in the base material. The highest $\Delta \mathrm{K}$, which is near twice that of the base material, was observed for cracks originating $6 \mathrm{~mm}$ from the plate joint line. At this position, the crack propagates about 15 times more than in the base material. The differences in the fatigue crack growth rates and threshold values ( $\Delta \mathrm{K}$ th) would have been due to weld residual stress. Bussu et al. [78] have also shown that mechanical stress relief is possible with stretching by $2 \%$ to make the crack growth rate almost equal to that of the parent base material. Crack growth rates have been shown by Donne et al. 81 to have little or no dependence on hardness, microstructure, or pores.

\subsection{XXX ALUMINIUM ALLOYS}

Microhardness profiles across the weld of AA5083-0 reported by Karlsson et al. [82] and Sato et al.[83] show that microhardness varied between 60 and $80 \mathrm{HV}$. Kumagai et al. [84] showed that a hardness increase of about $6 \%$ was obtained in the weld nugget of 5083-H112 due to fine grains caused by FSW.

Tensile specimens of 5083-H111 tested in transverse direction usually fail in the base materials because hardness and strength of the weld are higher than that of the parent material. Hence, tests are carried out in the longitudinal direction, with the gauge length being the entire weld material, to study the effect of process parameters on tensile properties. UTS, yield strength, and elongation results were compared by Kumagai et al. [84] for FSW and MIG of AA5083 with that of the parent material. They showed no significant difference in both mechanical properties and microhardness profiles. Slightly different results were obtained for severely strained $5083-\mathrm{H} 131$ by Colligan et al. 85 where tensile fracture location was in the weld, as softening in the weld nugget was brought about by frictional heat, especially in the flow arm zone. This caused a decrease in yield strength 


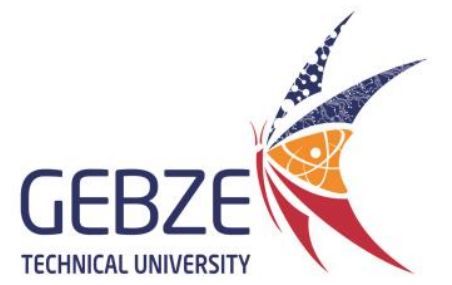

Acta Materialia Turcica

Volume 4, October 2020, Pages 1-39

by $44 \%(155 \mathrm{MPa})$, compared to that of the parent material.

Paik [55] compared the tensile properties of fusion welded and FSW samples of 5083-H112 and 5383-H116. The results are shown in Figures 12-13. Tensile properties of the welds were lower than those of the base materials; then, FSWs tensile properties were superior to those of gas-metal arc-welding (GMAW) for the two similar materials. Reduction in mechanical properties was more significant for 5083 than 5383 which are competing high strength alloys for marine applications.

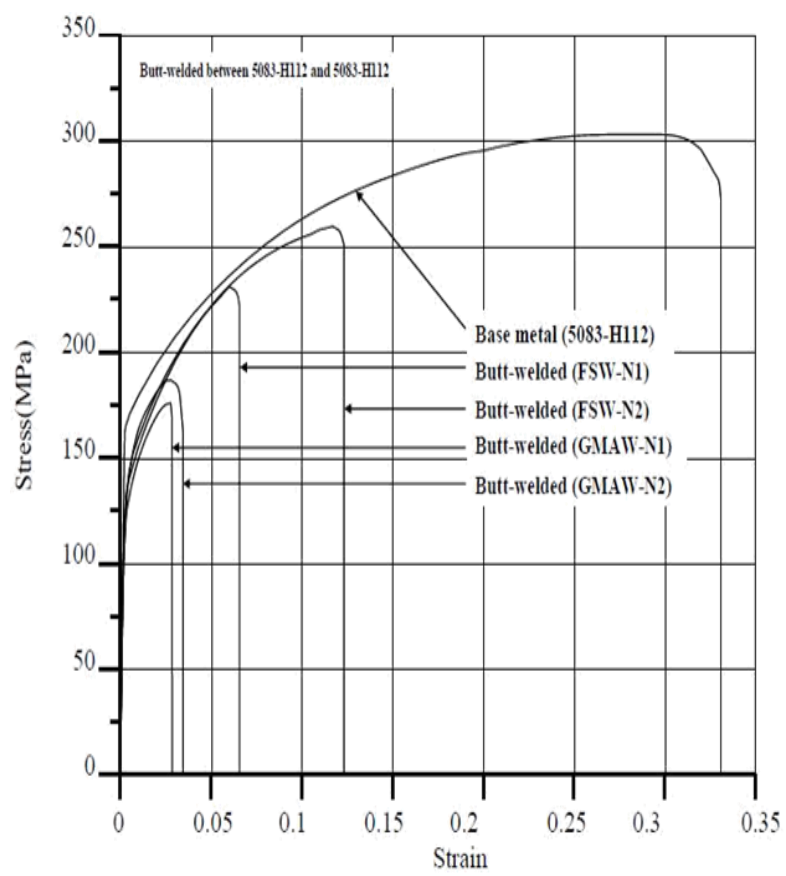

Figure 12. Engineering stress-strain curves for the base material, FSWs, and GMAWs of 5083-H112 [55].

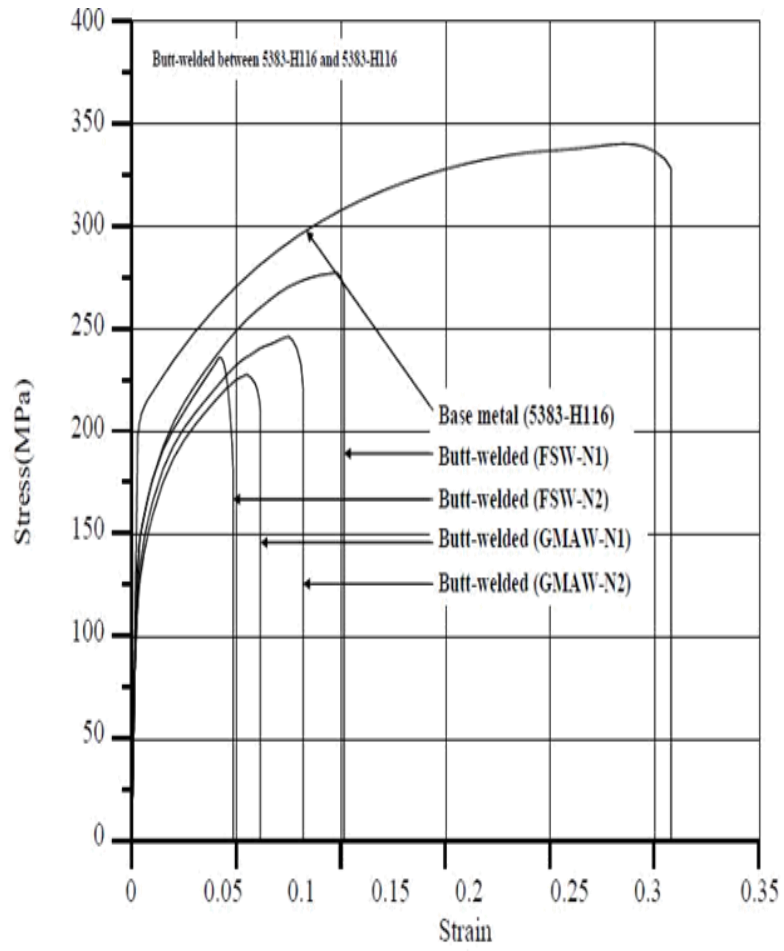

Figure 13. Engineering stress-strain curves for the base material, FSWs, and GMAWs of 5383-H112 [55].

Fatigue testing results of FSW, MIG, and parent materials of AA5056 investigated by Zhou et al. [2] are shown in Figure 14. Fatigue resistance of both welds at 2 $\times 10-6 \mathrm{MIG}$ weld was $42.32 \mathrm{MPa}$ for MIG compared to 68.47MPa for FSW. This showed that FSWs were better than MIG in terms of fatigue properties. 

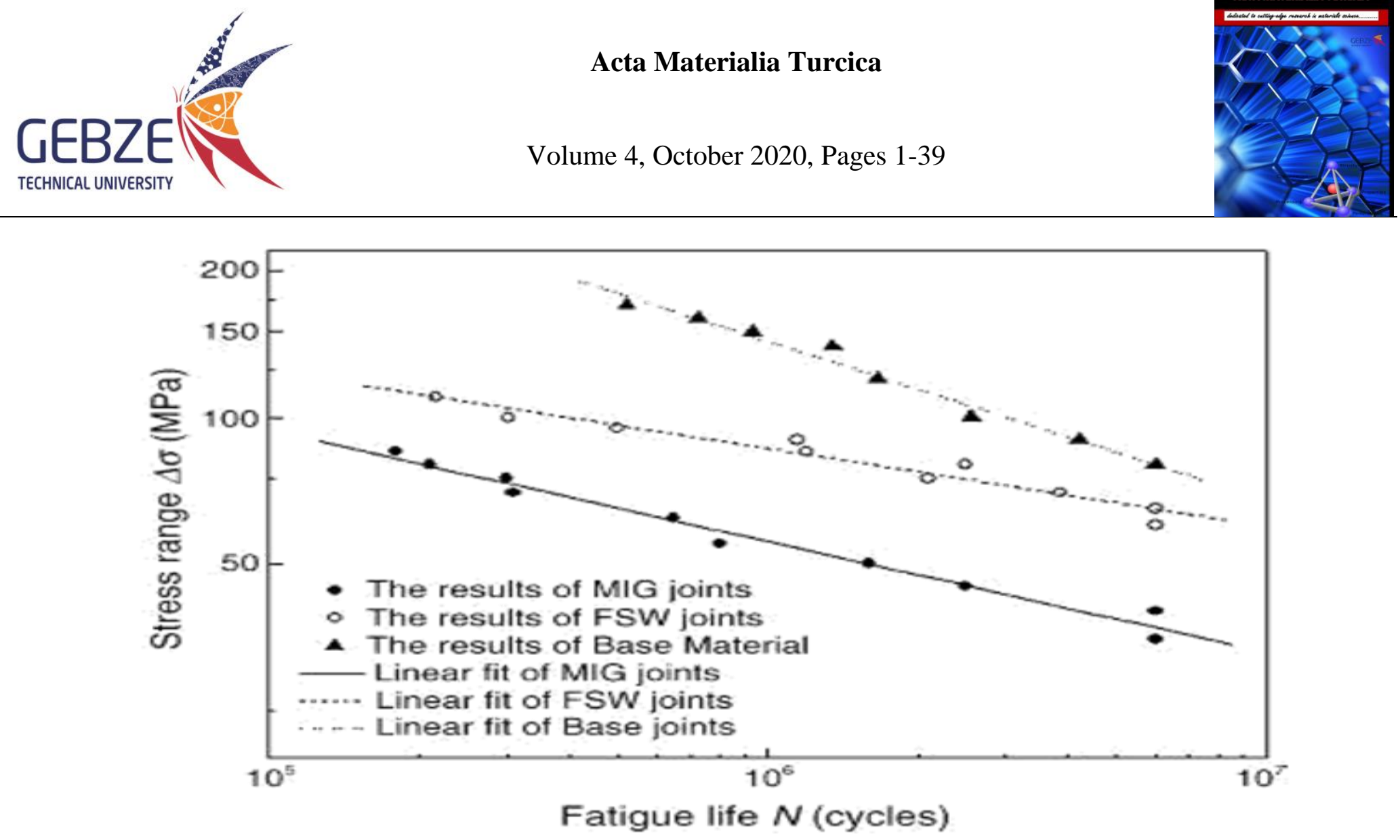

Figure 14. S-N curves for AA5056 MIG welded FSW and parent material [2].

James et al. [86] studied the effect of welding speed on the fatigue life of FSW AA5083-H321. They reported that in both as-welded and polished specimens, the fatigue limit at 107 cycles decreased by $11 \%$ for polished and $19 \%$ for as-welded specimens when welding speed increased from 80 to $200 \mathrm{~mm} /$ minute, as shown in Figure 15. Lower values of fatigue limit for as-welded specimens were ascribed to texturing of the onion skin, at the crown surface of the weld, which influenced crack initiation. At higher speeds, the textures were pronounced and acted as prominent discontinuities for fatigue crack initiation and greatly reduced fatigue resistance. An example is shown in Figure 16.

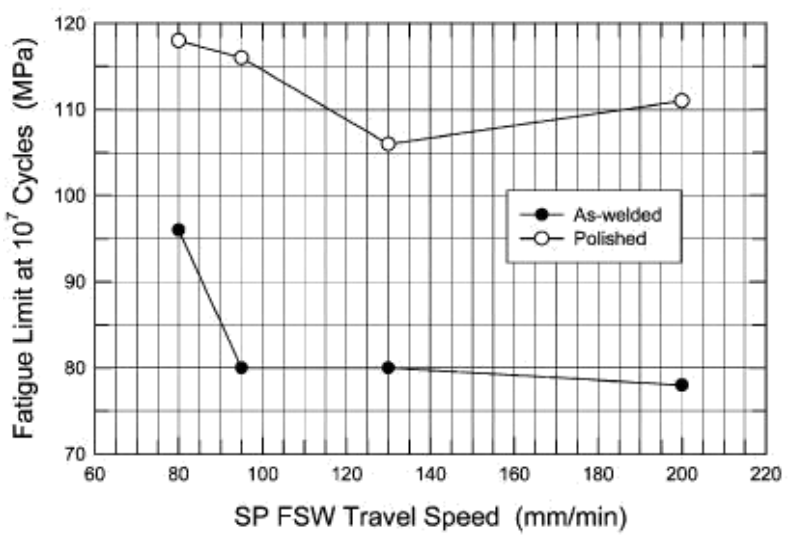

Figure 15. The relationship between fatigue limit at 107 cycles and FSW travel speed [86]. 


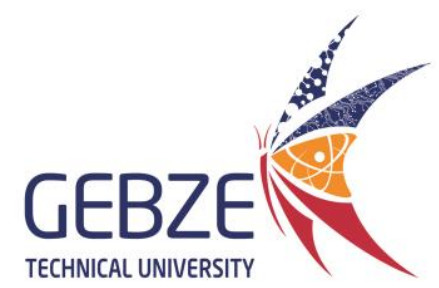

Acta Materialia Turcica

Volume 4, October 2020, Pages 1-39

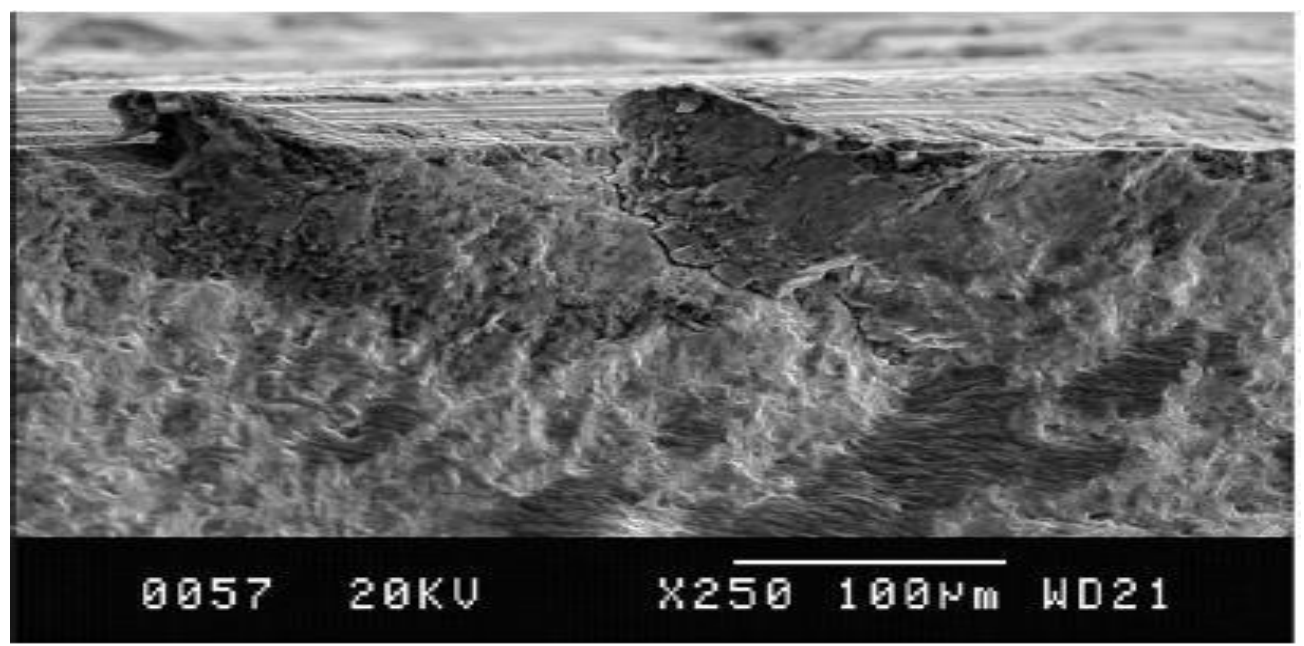

Figure 16. Surface notches from onion skin associated with crack initiation [86].

\subsection{XXX ALUMINIUM ALLOYS}

The shallow "W" hardness distribution across the weld is typical for FSW Al6013 and other alloys as described by Juricic et al. [87], Mishra et al. [6] and Zhou et al. [2]. The HAZ hardness minima of both sides (advancing and retreating) of the weld, and in the weld nugget were about $35 \%$ and $26 \%$ lower than the hardness of the base material respectively. The T6 and T4 conditions were welded and heat-treated to $\mathrm{T} 6$ condition. As a result of this treatment, hardness values increased, nearing that of the parent material, but HAZ hardness minima were still present. HAZ hardness minima in the T6 to T6, and T4 to T6 reaging treatment were $120 \mathrm{HV}$ and $104 \mathrm{HV}$ respectively. Low hardness bands were detrimental to the fracture toughness of the weld if a crack is located therein. The hardness results indicated that the weld zone was softer than the base material, even after post-weld heat treatment (PWHT). As previously shown for $2 \mathrm{XXX}$ series alloys [74-77], hardness through the thickness of the weld zone also varied for 6XXX alloys, even in the PWHT condition. Heinz et al. [32] proved this for FSW of 6013 in both T4 and $\mathrm{T} 6$ conditions given PWHT for $4 \mathrm{~h}$ at $190^{\circ} \mathrm{C}$. The soft zone extended $10 \mathrm{~mm}$ on the crown surface and $6 \mathrm{~mm}$ at the root surface at both sides of the weld centerline.
FSW transverse yield and tensile strength values in the naturally aged condition reported by Heinz et al. [32] were 160 and $300 \mathrm{MPa}$, which are $75 \%$ and $85 \%$ of that the parent material. PWHT values of 6013-T4 artificially aged to T6 reported by Juricic et al. [87] and Lohwasser et al. [77] showed yield strength of $340 \mathrm{MPa}$ and tensile strength of $370 \mathrm{MPa}$, almost approaching that of the parent material. Mishra et al. [1] stated that mechanical property values for naturally aged $6013 \mathrm{Al}$ were inconsistent. This may have been due to the advancement in tool design, process control, and many other unreported boundary conditions.

Fatigue data for $6013 \mathrm{Al}$ by Magnusson et al. [76] is shown in Figure 17. They derived the fatigue life data for $6013 \mathrm{Al}$ performed at $\mathrm{R}=0.1$ and specimens with a $5 \mathrm{~mm}$ hole creating a stress concentration $\left(\mathrm{K}_{\mathrm{t}}\right)$ of 2.5 for 6013T4 parent material, in welded plus PWHT to T6 condition [76]. FSW had reduced the fatigue life of the sheet. Surface milling restored the apparently applied threshold stress to the same level as the un-notched parent material $\left(\mathrm{K}_{\mathrm{t}}=2.5\right)$. Also, in the as-weld and $\mathrm{T} 6$ aged condition, the fatigue life curve was still above the reference curve for the open hole specimens of the parent material $\left(K_{t}=2.5\right)$. 

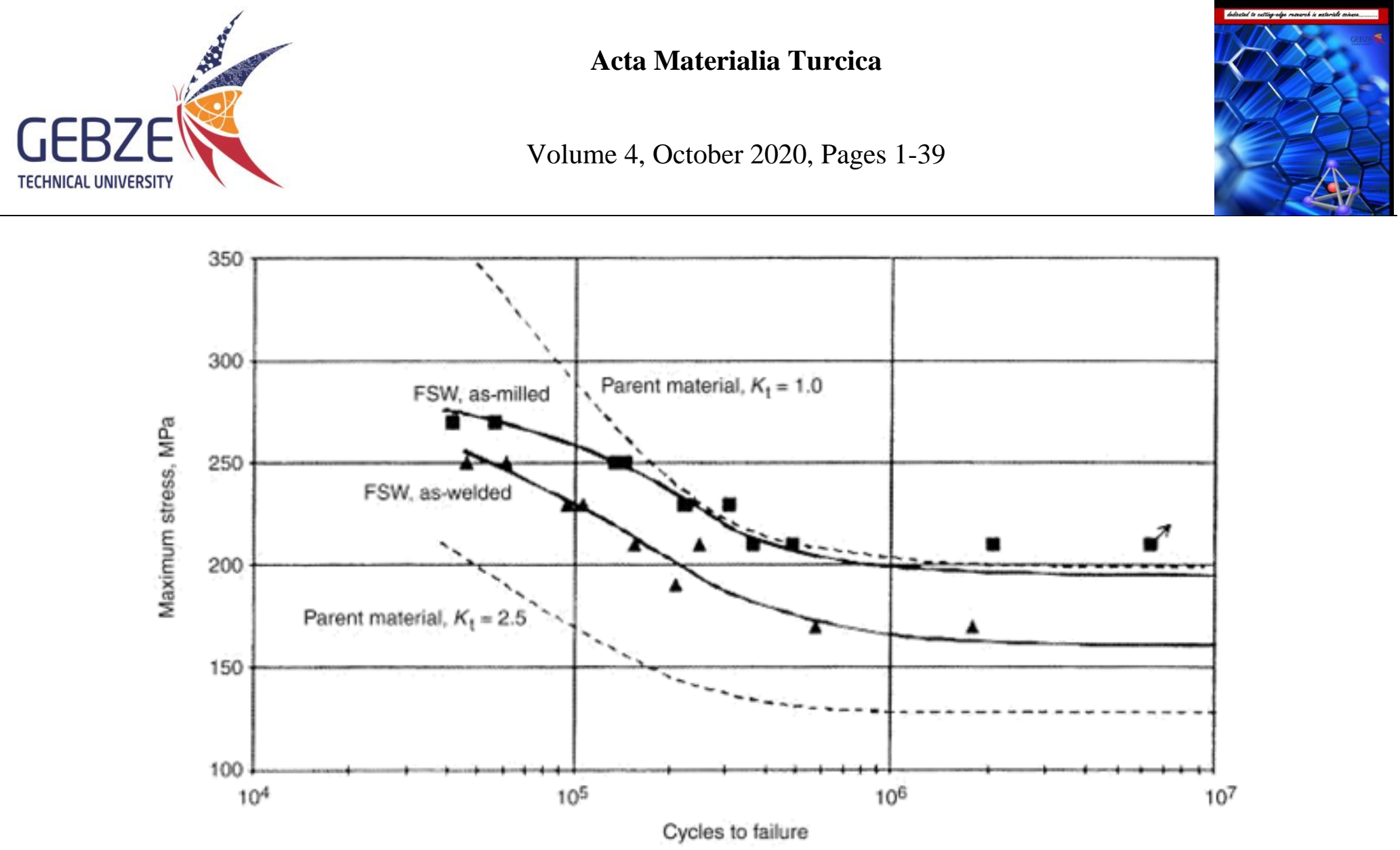

Figure 17. $\mathrm{S} / \mathrm{N}$ curve for 6013-T6 FSW (as-welded and milled) and parent material (at stress concentration, $\mathrm{Kt}=1$ and 2.5) all at $\mathrm{R}=0.1[76]$.

Experiments with the same alloy $(6013 \mathrm{Al})$ and PWHTs were performed by Juricic et al.[87]. Fatigue crack propagation curves for three heat treat conditions (T6 FSW naturally aged for 4 weeks, T4 FSW and PWHT to T6, T6 FSW subsequent to re-ageing $\mathrm{T} 6$ at $190^{\circ} \mathrm{C}$ ) at $\mathrm{R}$ $=0.1$ and $\mathrm{R}=0.7$. Slots were introduced at the center of the weld nugget and parallel to the weld direction. At $\mathrm{R}=$ 0.1 , crack growth rates in the welded samples were faster than in the parent material. At $\mathrm{R}=0.7$, the crack growth rates were almost the same as in the parent material. The highest fracture toughness was reported when the crack was located in the center of the joint welded in T6 temper and afterward naturally aged. T6 heat treatment after welding had a detrimental effect on fracture toughness even though it increased the joint strength.

\section{MICROSTRUCTURE EVOLUTION AND MECHANICAL PROPERTY DISTRIBUTION IN FSW}

\section{ALUMINIUM ALLOYS}

The microstructure and mechanical properties found in FSW zones are largely dependent on the following:

- Alloy composition: This determines the availability of strengthening mechanisms [1].

- Alloy temper: This dictates the starting microstructure and how temperature and strain history affects the precipitation sequence in the different microstructural zones during welding. This was described in Section 2.4 where differences in hardness after PWHT to T6 were recorded for 6013 welded in both T4 and T6 temper conditions [1,15]. However, after FSW of 2024 in T351 and T6 conditions, Genevois et al. [14] concluded that the initial state of the aluminium sheets had no influence on mechanical properties across the zones since they followed similar an evolution in terms of hardness profile and grain structure. 
- Welding parameters: Rotational and welding speeds for a given thermal boundary and tool geometry determine the temperature and strain history of the material being welded. This affects the level of misorientation, grain size, and precipitate distribution $[1,15]$.

- Tool design: This includes shoulder diameter, pin diameter, and pin length, where the shoulder may be scrolled or concave [1]. Rodrigues et al. [88] and Fujii et al. [89] have reported varying mechanical properties of FSW sheets of the same alloy performed at similar welding parameters. Tool design is partly one of the identified factors causing it.

- Material Thickness: This affects the rate of cooling from the peak temperature. Biallas et al. [74] recorded hardness differences for different sheet thicknesses of 1.6 and 4mm $2024 \mathrm{Al}$. Higher maxima and lower hardness minima were obtained for the $4 \mathrm{~mm}$ sheet, as well as higher hardness differences through the sheet thickness. Not only was the cooling rate higher in the thin sheet, but also the temperature gradient was small, giving rise to higher hardness minima.

- Welding fixtures: The thermal conductivities of the clamping system and other fixtures directly contacting the weld also affect the rate of cooling [1].

- Post Weld Heat Treatment (PWHT): This depends on the temper and composition of the alloy, as well as the time between welding and testing. Non-heat treatable alloys do not age either naturally or artificially, so their properties are stable with time. In contrast, $2 \mathrm{XXX}$ alloys will stabilize within a few days, $6 \mathrm{XXX}$ will not stabilize until after several days, while 7XXX aluminium alloys will continue to change in properties almost infinitely unless an artificial post-weld heat treatment is carried out [1].

FSW parameters can be modified to achieve the desired microstructure and property distribution $[1,88]$. The four microstructural zones which were highlighted in previous Section 1.1 (parent material, HAZ, TMAZ, and weld nugget) were present in all cases of friction stirred aluminium alloys $[1,63,90,91]$. The FSW weld nuggets are usually inhomogeneous, containing banded microstructures usually associated with the tool design and tool advance per revolution (i.e. tool pitch). Deformation of the material in the weld nugget not only increases the dislocation density, but also the amount of grain surface and grain edge per unit volume [10]. There were variations in grain size, bandwidth, and particle distribution as a function of process parameters [1]. As a result of varying thermo-mechanical conditions through the joint, corresponding variations in microstructure and mechanical properties have been observed [1,14]. The peak temperature achieved in the weld nugget and the quenching rate from the peak temperature is principal product variables that govern the microstructural evolution across the weld. The nugget may be left in [1]:

- an over-aged condition, which negatively impacts on the hardness of the nugget,

- a partial solution treated condition, which results in some hardness if post-weld ageing is performed, or

- a single-phase solid solution, in which post-weld ageing enables recovery of properties similar to the base metal.

FSW results in the redistribution of intermetallic phases (e.g. $\mathrm{Mg}_{2} \mathrm{Si}, \mathrm{Mg}-\mathrm{Si}-\mathrm{Al}-\mathrm{Cu}, \mathrm{CuAl}_{2}, \mathrm{Al}_{2} \mathrm{CuMg}$, and AlMn) which impacts, on the mechanical properties, including the fatigue crack characteristics within the weld [14]. It has been reported [6,16,17] that the Hall-Petch effect [92] was not dominant in determining hardness, and instead, dislocation density in work-hardened solutiontreated alloys and dispersion hardening in non-heattreatable alloys, such as 5083, had a higher effect. The hardness distribution in heat-treatable alloys can be mainly explained by the size, density, and distribution of the strengthening precipitates, which are dependent on local thermal hysteresis during welding [14-17,83]. Tensile properties are those at the fractured position. The fracture usually occurs in areas with the lowest hardness, where there is an uneven hardness distribution, otherwise, fractures occur at areas with the lowest mean value of Taylor factors [17], which are affected by composition and microstructure. Variation in hardness within the weld nugget has also been reported [18,93], due to the difference in the distribution of precipitates within the onion ring structure.

\section{1. $2 X X X$ ALUMINIUM ALLOYS}

2XXX series aluminium alloys are usually characterized by the advancing and retreating sides, and hardness minima (in the HAZ) and maxima (near TMAZ), which are separated by a local hardness maximum (in the weld nugget). There are local maxima between the HAZ inner and outer minima on both sides of the weld nugget, as shown in Figure 18. The depths of the minimum are dependent on process parameters, as shown in Figure 19. Jones et al. [18] reported that artificially aged tempered alloys were strengthened primarily by very fine needles of the $\mathrm{S}^{\prime}\left(\mathrm{Al}_{2} \mathrm{CuMg}\right)$ phase defined as the GPB (Guinier- 


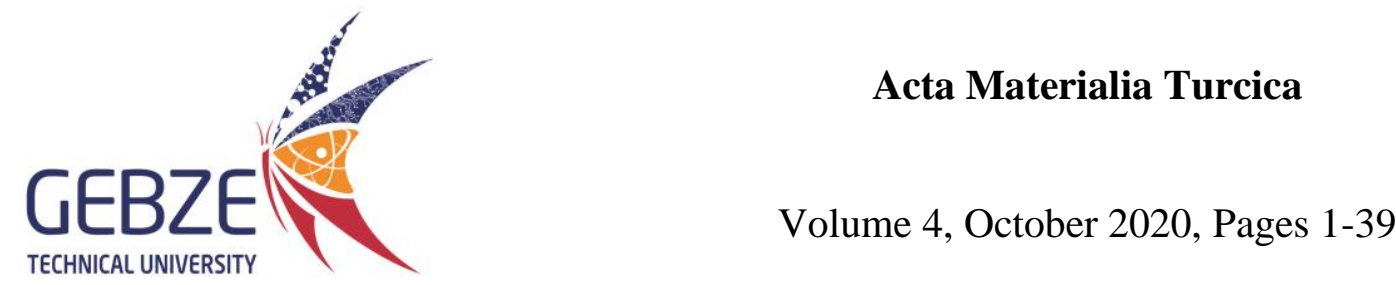

Preston Bagaryatskii) zones. The hardness minimum resulted from over-aged and coarse $\mathrm{S}$-phase $\left(\mathrm{Al}_{2} \mathrm{CuMg}\right)$ particles; the local hardness maxima were caused by the presence of fine S-phase precipitates, and the outer hardness minimum was due to no precipitates, even after post-weld natural ageing. Similar results have been reported [14,94]. Achieving maximum nugget strength is dependent on welding power being sufficient for the production of solution treated and naturally aged materials $[1,18]$. Grain sizes of about $4-5 \mu \mathrm{m}$ of an entirely recrystallized weld nugget have been reported by Jones et al. [14] and Genevois et al. [18], while grain sizes in the range $5-15 \mu \mathrm{m}$ were recorded by Ali et al. [94].

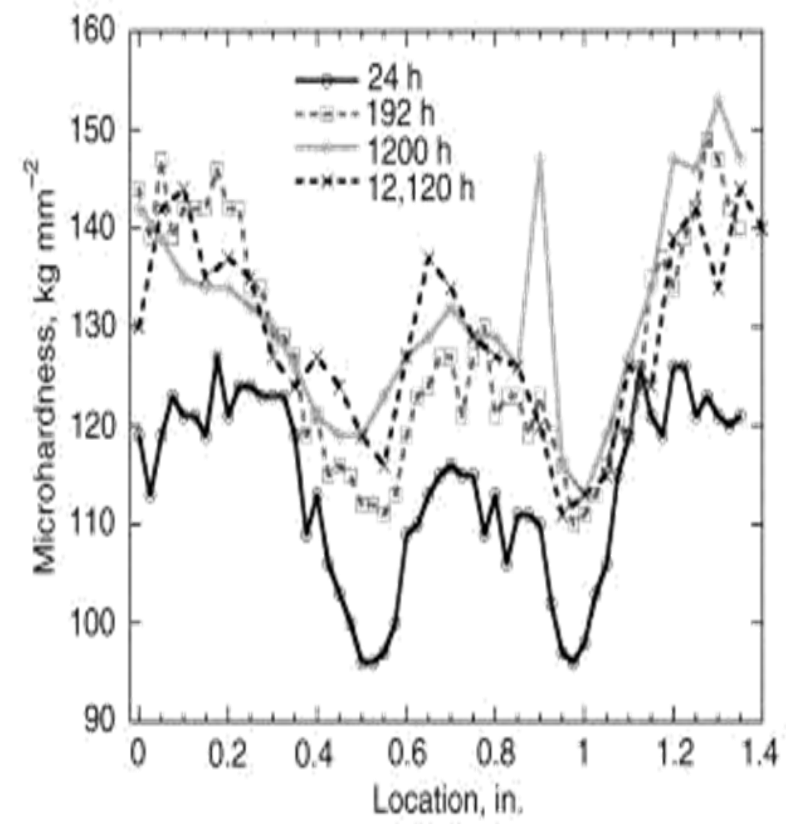

Figure 18. Hardness profile for 2024 after natural ageing $>7$ months [1].

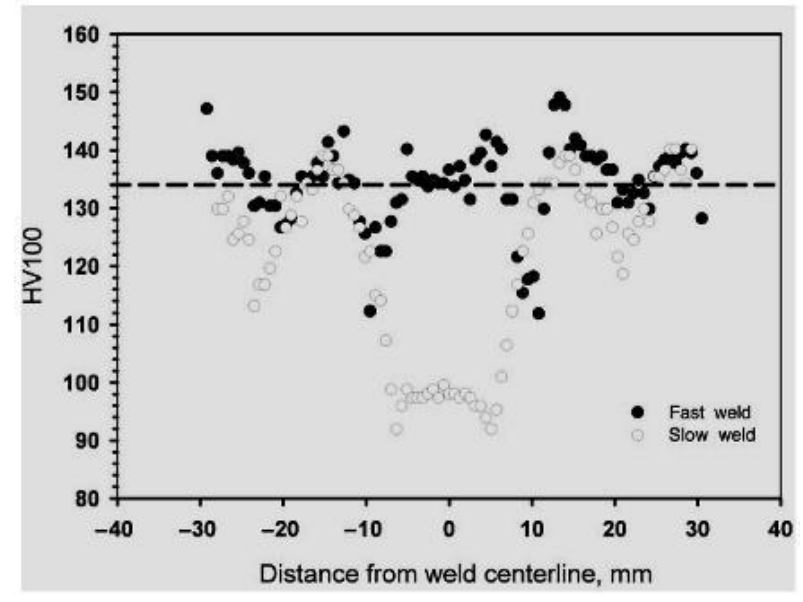

Figure 19. Transverse hardness distribution in 2524T351 in slow and fast welds [1].

\subsection{XXX ALLOYS}

The FSW of O-temper based material of 5XXX leads to the formation of finer grains than the parent material [95]. After welding of strain-hardenable alloys 5XXX-H0 in the annealed condition, the microstructure was stable and no softening occurs in the weld nugget and HAZ. In the strain-hardened condition (H111, H131, H32, and so on), the work-hardened structure recrystallized during welding and softening sometimes occurred. The sensitivity of non-heat-treatable alloys to welding parameters is dependent on the base material [95].

Mechanical properties differentials result from changes in grain size, dislocation density following plastic deformation which results from thermal cycling, and recrystallization of the weld. Thermal cycles may give rise to grain coarsening in the HAZ which results in a decrease in mechanical properties.

In FSW of AA5182-H111 and AA5083-H111, Tronci et al. [96] concluded that grain size in the TMAZ and advance per revolution had a linear relationship. In FSW AA5183-H111, lower grain sizes were obtained for colder welding conditions (advance per revolution, APR<3.5), and larger grain sizes were obtained for hotter welding conditions $(\mathrm{APR}=11.0)$. They also observed that grain size in the TMAZ varied greatly with APR at APR $<3.5$ while at $\mathrm{APR}>3.5$, the variation was less significant. This implied that friction heat was approaching stabilization at APR $>3.5$, due to the decreased coefficient of sliding friction between the tool and the stirred material. More intense plastic deformation and frictional heating were 
obtained with the scroll shoulder tool at higher advance per revolution than when the conical tool was used. Hence, the recrystallized grain sizes obtained from the nugget of the former were higher owing to static grain growth, which depended on the maximum temperature during stirring. The maximum temperature was a product variable of the rotational speed and transverse speed. This explains the increase in grain size with increasing APR. Grain size in the TMAZ for AA5083 was found to be independent of welding parameters. The parent material grains in 5083 $(18 \mu \mathrm{m})$ were much finer than those in $5182(36 \mu \mathrm{m})$, hence the rate of recrystallization was higher giving rise to a fully recrystallized grain structure in the TMAZ of 5083. It was proven that the response of the alloy to recrystallization was dependent on the initial grain size of the material and strain rate. Tronci et al. [96] also showed that hardness evolution for AA5182 welds was dependent on the HallPetch relationship, while yield stress did not obey the same rule.

The microstructure of FS welded AA5056 investigated by Zhou et al. [2], the size of crystal grains in the weld nugget was $6 \mu \mathrm{m}$ compared to $35 \mu \mathrm{m}$ of the base material. They reported the grains diminishing gradually from the base materials to the weld nugget, indicated by the difficulty of obtaining clear micrographs from high magnesium content aluminium alloys. The weld nugget and TMAZ had a distinct boundary on the advancing side, while the transition was gradual on the retreating side. This was reported to have been due to the difference in the direction of velocities of rotation and translation on the advancing side and retreating sides of the tool. Microhardness profiles obtained for FSW compared to MIG are given in Figure 20. The microhardness minimum was at the fusion zone of the MIG welded sample, while it was at the TMAZ for the FSW specimen at the advancing side. The decrease in hardness at the TMAZ is attributed to dissolution and coarsening of strengthening precipitates, resulting from thermomechanical conditions. Dynamic recrystallization and recovery from strain hardening decrease the dislocation density.

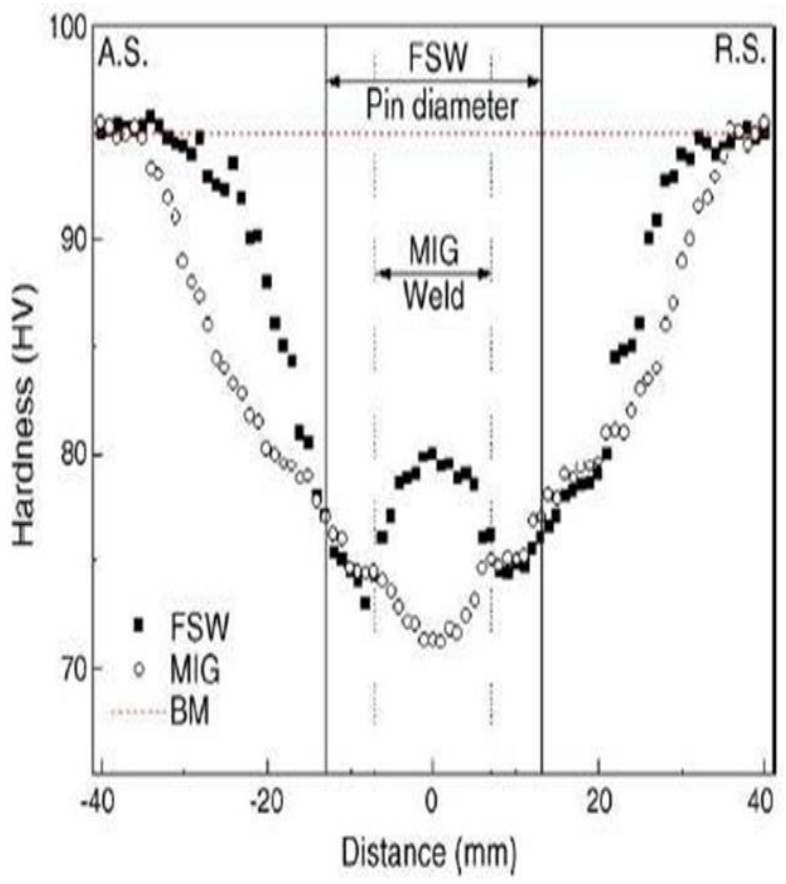

Figure 20. Microhardness profiles of AA5056 FSW and MIG welded [2].

Non-heat treatable aluminium alloys are generally insensitive to welding parameters [95]. The strength of tensile specimens of the O-temper sample loaded in the transverse orientation will be around that of the parent material, while strain hardened ones will exhibit the strength of the O-tempered ones, and strain and fracture will be localized in the weld and HAZ.

\subsection{XXX ALUMINIUM ALLOYS}

Heat treatment causes the precipitation of the strengthening $\mathrm{Mg}_{2} \mathrm{Si}$ and $\mathrm{Mg}-\mathrm{Si}-\mathrm{Cu}-\mathrm{Al}$ phases [1,97]. Naturally, aged FSW samples revealed a shallow 'W" hardness curve across the weld, as shown in Figure 21 $[1,9,72]$. Hardness reduction in the nugget, slightly less than $26 \%$ of the base material, was recorded by Juricic et al. [87], which implied that strength and ductility would be lower than that in the base material $[1,9,72]$. Welding in the T6 condition and subsequent PWHT to the T6 condition again resulted in a minimum hardness of 104 $\mathrm{HV}$ in the very narrow low hardness region in the HAZ. This narrow low hardness region resulted from over-aging during welding, which meant that re-precipitation of the 


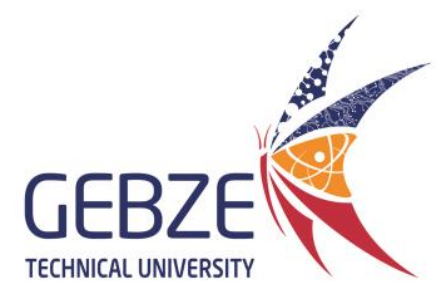

Acta Materialia Turcica

Volume 4, October 2020, Pages 1-39

strengthening phase was lowest [17]. This could reduce the fracture toughness if cracks were located in the low hardness band [1]. As in other alloy types, dissolution, coarsening, and transformation of precipitates gave rise to complex hardness and strength variations across the weld. The minimum toughness was found at the boundary between the weld nugget and HAZ, due to the alignment and concentration of coarse particles at this point by the FSW process. This was proved in Kafali et al. [9] as fracture occurred mostly in the HAZ $[9,16,17,72]$. Sato et al. [16] showed that the weld nugget contained smaller recrystallized and equiaxed grains resulting from frictional heating and plastic flow, while TMAZ and HAZ consisted of partially recovered and deformed grains, shown by misorientations due to sub-grain boundaries and small-angle boundaries in the grain interior. Despite the expected difference in heat generated across the height of the nugget of FSW of AA6063-T6, the hardness variation was insignificant because of the high thermal conductivity of aluminium. The concentration of coherent needleshaped $\beta$ "GP zones and less coherent rod-shaped $\beta^{\prime}$ precipitates governed the hardness distribution, while small grain size and higher density of sub-grain boundaries merely made the weld nugget have a slightly higher hardness than a solution treated base material. The microstructure and characterization of precipitates obtained from the FSW zones were compared with results from simulated thermal cycles with different peak temperatures of different A16063 samples at different temperatures to understand the behaviour of precipitates at various thermal cycles. The stability of needle-shaped precipitates decreased with increasing local temperature in the weld area. This resulted in increasing hardness from the weld nugget (softened area) to the low hardness region
(TMAZ and HAZ) and the unaffected base material. In the low hardness region, needle-like $\beta$ "precipitates were found to have grown into rod-like $\beta^{\prime}$ precipitates. The reprecipitation of needle-like precipitates was unlikely during the weld's thermal cycle due to time limitation (about $220 \mathrm{~s}$ at $200^{\circ} \mathrm{C}$ and $90 \mathrm{~s}$ at $300^{\circ} \mathrm{C}$ ) [16]. Increased grain sizes from the weld nugget to the base material, as shown in Figure 22-23, had no noticeable effect on hardness results.

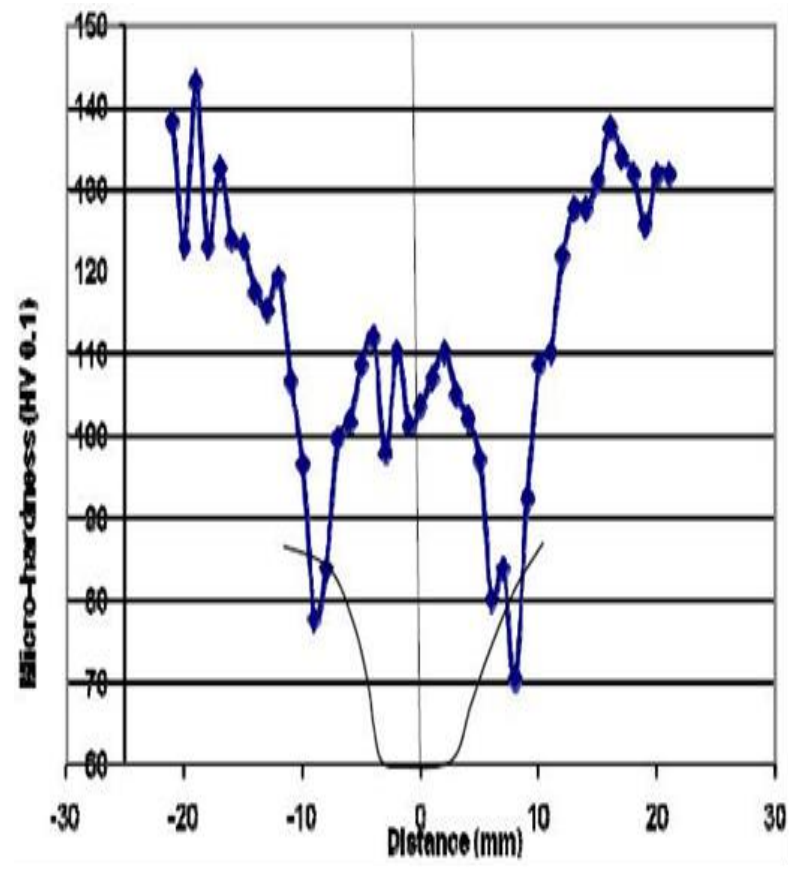

Figure 21. Hardness profile in PWHT FSW of AA6013 [9]. 


\section{Acta Materialia Turcica}

Volume 4, October 2020, Pages 1-39



Figure 22. The macrostructure of standard FSW of AA6013 showing the different zones [9].
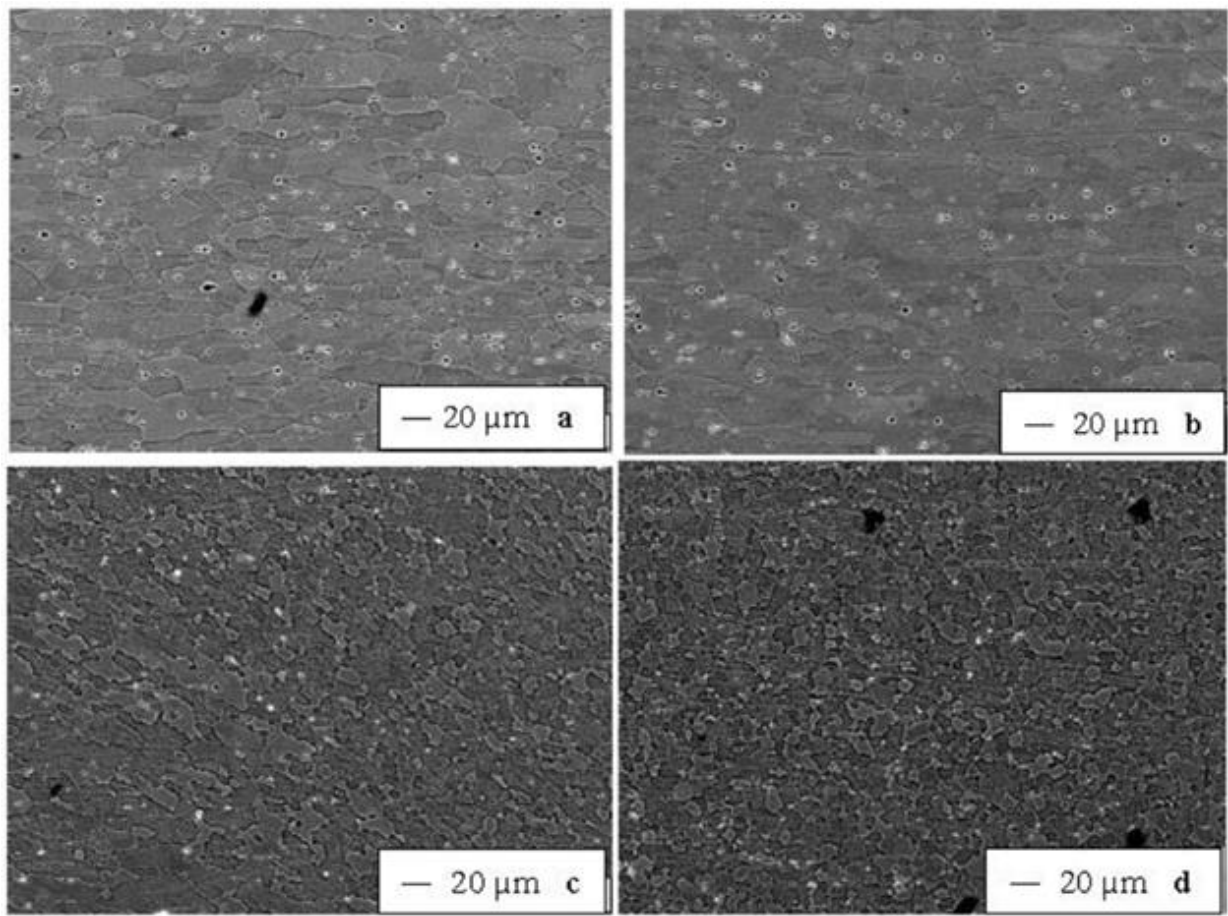

Figure 23. The microstructure of standard FSW plates of AA6013 showing: (a) Base metal, (b) HAZ, and (c) TMAZ, and d) Weld nugget [9]. 


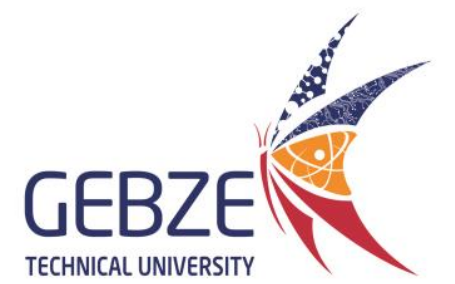

Acta Materialia Turcica

Volume 4, October 2020, Pages 1-39

\section{THERMAL HYSTERESIS AND WELDING PARAMETER DEPENDENCY IN FSW}

"Thermal hysteresis" is a phenomenon common in FSW process which influences the resulting microstructure across the weld, especially the precipitate distribution [19]. The maximum temperature of the weld increases which increasing rotation speed, without any proven relationship with the starting temper of the base material, but this maximum temperature is not reached until about a few seconds. This has been demonstrated by Yutaka et al. [15] in a closely monitored FSW of $6063 \mathrm{Al}$ where thermocouples were installed at the base along the butt joint line. It took about $10 \mathrm{~s}$ for the process temperature to rise from room temperature to each maximum value at all rotation speeds. As illustrated in Figures 24 and 25, the heating and cooling curves roughly overlap each other, with the maximum temperature rising sharply with increasing rotational speed at fixed welding speed, up to a maximum of 2000rpm where the rate of increase gradually becomes insignificant [15].

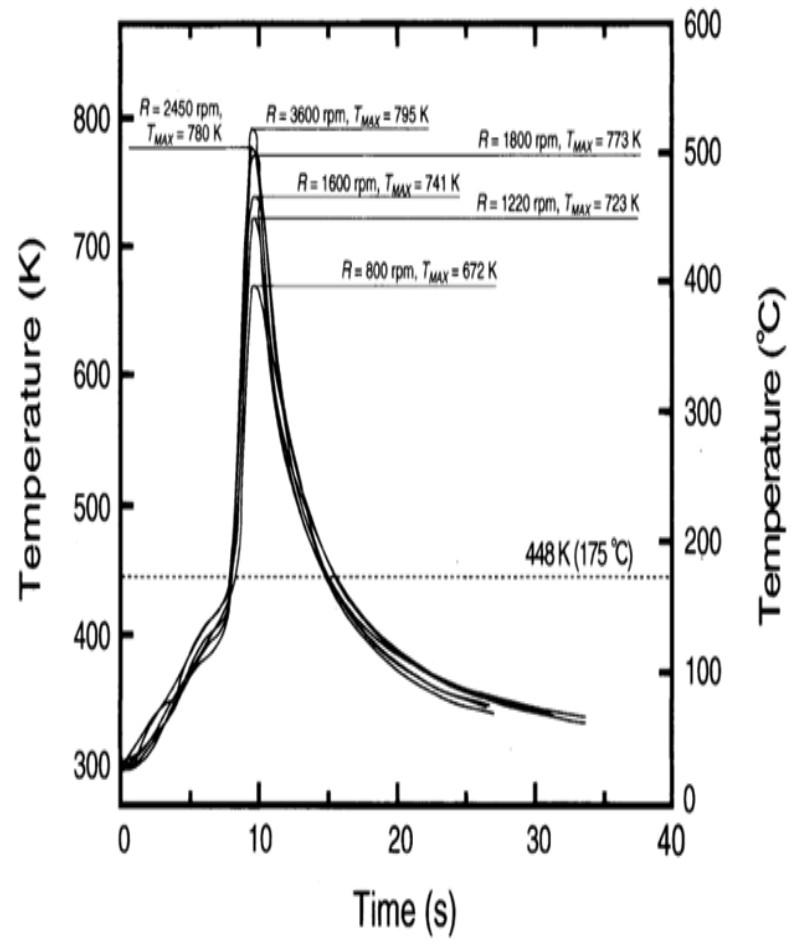

Figure 24. Thermal histories during friction stir welding at the several rotation speeds of $6063 \mathrm{Al}$ with their respective maximum temperatures (Tmax) [15].

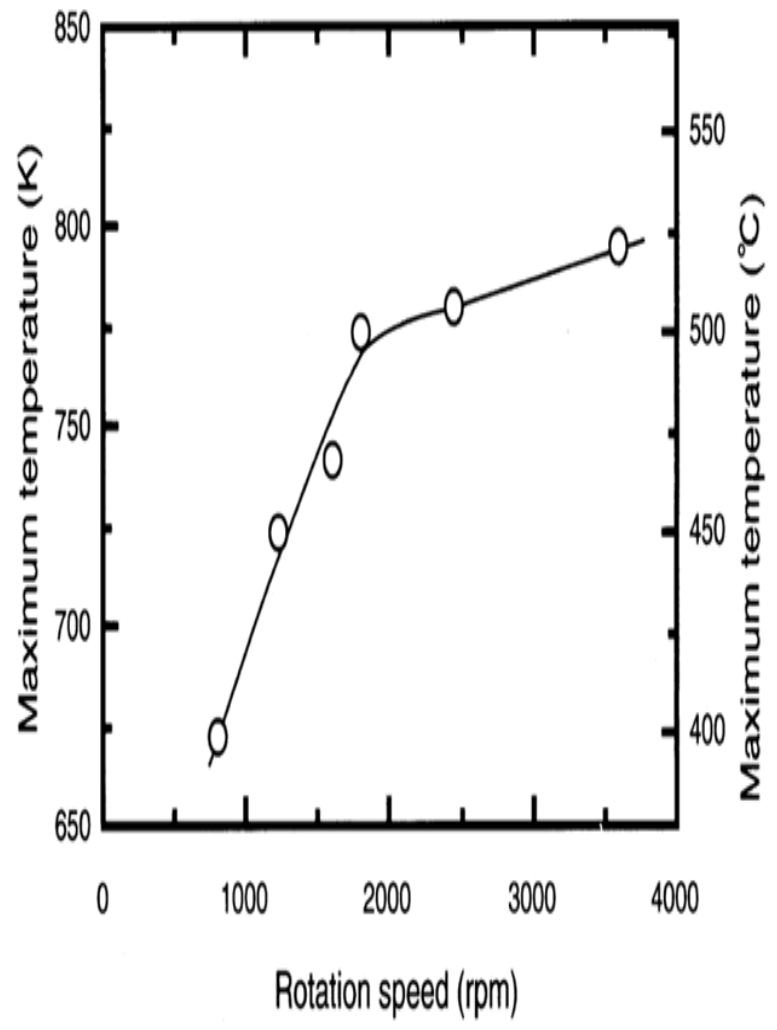

Figure 25. The relationship between welding rotation speed and the maximum temperature of the welding thermal cycle [15]. 


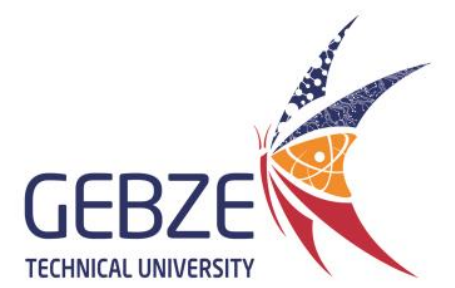

Acta Materialia Turcica

Volume 4, October 2020, Pages 1-39

\section{FATIGUE ASSESSMENT AND FRACTURE TOUGHNESS OF FSW}

\subsection{FATIGUE ASSESSMENT OF WELDED STRUCTURES}

In all engineering materials, including welded aluminium structures, damage due to fatigue starts in the micro-level, then becomes visible because plastic deformation results in the formation of micro-cracks on the slip bands. Coalescence and propagation of minicracks follow $[98,99]$. Fatigue failures are the most common causes of mechanical failure in aircraft structures [100]. Since welds are usually not perfect, fatigue failures in welded structures appeared mostly in the welds rather than in the base material, even when there were obvious notches and re-entrant corners in the latter. Hence, good and reliable fatigue assessment is of high practical importance in all structures where cyclic loads are expected, because it is critical to safety, especially in aerostructures $[99,100]$. Proper fatigue design comprises synthesis, analysis, and testing with or without computeraided design [101]. Fatigue assessment entails comparing the stresses and environmental influences that airframe structures are required to sustain with their likely resistance. Hence, the welded structures must possess resistance to withstand these stresses without failing. In the design of welded structures, the fatigue lives are assessed by the following methods 102 :

- S-N curves for specific welded joints used in conjunction with nominal stresses,

- S-N curves for welds used in conjunction with local notch stresses, and

- S-N curves for welds used in conjunction with hotspot stresses.

Fatigue resistance data are usually expressed by the S$\mathrm{N}$ curve, which is a plot of nominal applied cyclic stress range, $\mathrm{S}$, and the corresponding number of cycles, $\mathrm{N}$, to failure. These data indicate the maximum amount of load fluctuations that a structure can resist before failure in the design life resulting stress range. S-N curves are derived from linear regression analysis of $\log \mathrm{S}$ versus $\log \mathrm{N}$ fatigue data to establish mean curves and statistical lower bounds, usually mean-2-standard deviation of $\log \mathrm{N}$ to obtain the form:

$\mathrm{SmN}=\mathrm{A}$

where the constants $\mathrm{A}$ and $\mathrm{M}$ are the fatigue capacity and fitting power respectively [103].
The curves cover stress levels corresponding to the static design limit for the material (welded joint) to a fatigue endurance limit. The disadvantage is that the differences in stress amplitudes are not taken into account.

Palmgren-Miner's rule is usually applied where it is assumed that the fatigue damage due to ni cycles is directly proportional to ni/Ni. The stress history experienced by the structure (airframe) is usually computed by identifying the loading history from strain gauge measurement or finite element analysis (FEA) and extracting recognizable stress cycles from the stress spectrum.

The first method of fatigue assessment, which is most developed and standardized, has been commonly used in assessing the integrity of FSWs [30,32], which entails obtaining S-N curves from fatigue tests on specimens containing the weld detail (FSW) of interest. Fatigue design curves are obtained, taking into account the scatter of fatigue behaviour and providing a reference curve with a probability of survival at least equal to $97.7 \%$ [30]. The design curve is usually taken as the mean with a two standard deviation extensions on either side of $\log \mathrm{N}$. In codes and standards, the curves are identified by the fatigue strength at $2 \times 106$, the slope of $\mathrm{m}$ of the S-N curve as in the draft Euro-code [104] which are most consistent experimental data, or by arbitrary letters such as Class A, B, C by the Aluminium Association [102]. However, for FSW, no general overview is available to assist structural designers in determining design strength values or their dependence on welding parameters and material specification [30].

\subsection{FATIGUE BEHAVIOUR OF FSW ALUMINIUM JOINTS}

Improvement in fatigue strength of FSW over other processes, as mentioned in Section 1.1, offers superior joint integrity, and hence, higher reliability and damage tolerance, which are critical concerns in lightweight aerospace, marine, and automotive manufacturing. According to Lomolino et al. [30], this superiority is aided by the absence of filler materials, which can be responsible for potential notch effects and misalignment features. Fatigue values obtained from various tests approach the base material values [30]. Fatigue failures in FSW have often been observed to initiate from surface roughness, pronounced tool marks or lips, flash on the surface of the joint, or typical defects such as lack of penetration (LOP) as mentioned in Section 1.3. 


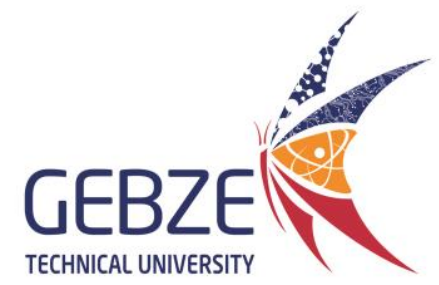

Acta Materialia Turcica

Volume 4, October 2020, Pages 1-39

Factors affecting the fatigue strength of the FSW aluminium joint include:

- Stress ratio, $\mathrm{R}$,

- Parent material condition,

- Temper condition,

- Surface condition,

- Presence of defects, and

- Residual stresses.

Increased in FSW transverse speed and decrease in welding speed is related to slight increases in high cycle fatigue because they are associated with low heat inputs which result in faster cooling rates of the welded joints $[3,30,105]$. This limits the microstructural changes, thereby affecting the local strength across the weld. Naturally, aged FSW joints show superior fatigue performance compared with artificially aged ones for the same alloy composition. Stress ratio was also identified as a factor influencing fatigue performance, for example in AA6082 (tested with $\mathrm{R}=0.5$ and $\mathrm{R}=-1$ ) [30]. Improvement in fatigue strength at $2 \times 10-6$ cycles has been reported for tests carried out with a negative stress ratio because stress applied is partially compressive [30]. Surface conditions are also important; according to Kahl et al. [71], the height of burrs and the transition from large grains in the statically recrystallized layer on the profile surface to small grains of dynamically recrystallized nugget determined the time of crack initiation. This explains the lower fatigue strength associated with asweld surfaces, compared to polished specimens. To improve fatigue properties, mechanical machining of the weld surface is advised, as surface roughness reduces fatigue strength because crack initiation is usually associated with the spiral features created by the tool or a stress concentration associated with the weld flash. For practical purposes, a slightly rough surface or small undercut still offer advantages over conventional welding processes. The presence of defects also plays a major role; it has been shown that AA6082-T6 specimens with weak bands of oxides had higher fatigue resistance compared with those with strong bands of oxides, except for tests performed at the highest test amplitudes [71]. Zhou et al. [103] proved that the fatigue characteristics of Al 5083 and Al 2024 at $2 \times 10-6$ cycles decreased from $100.3 \mathrm{MPa}$ to 65.6 as a result of kissing bonds (joint line remnants made of oxides) and 120.6 MPa to 54.7 MPa, as a result of root flaws.

\subsection{FRACTOGRAPHY OF THE SURFACES OF FSW FAILED SPECIMENS}

Fractures surfaces are usually characterised by using the SEM in secondary electron mode to see the topography. In FSW experiments, fractographs of tensioned specimens show the inherent failure mode and mechanical behaviour of the weld, while those of failed fatigue specimens provide information on the location of crack initiation and pattern of propagation under cyclic loading. Macroscopic morphology and microscopic mechanisms are often reported [70]. Observations by Singh et al. [63] revealed dimpled surfaces, indicative of high ductile behaviour, in all FSW AA6082-T651 specimens at various rotational and transverse speeds. Deeper and fewer dimples and larger second phase particles were observed in welds done at lower rotational and transverse speeds, while more shallow dimples were present on surfaces of those done at higher speeds (Figure 26). The latter is indicative of higher tensile strength. In the same vein, Srivatsan et al. [70] reported that the overall morphology was brittle, with failure occurring normally to the far-field stress (stress far away from the stress raiser) axis on tensile fractured samples of 2024-T8 FSW. At higher magnification, local ductile failure and brittle failure mechanisms were reported. 


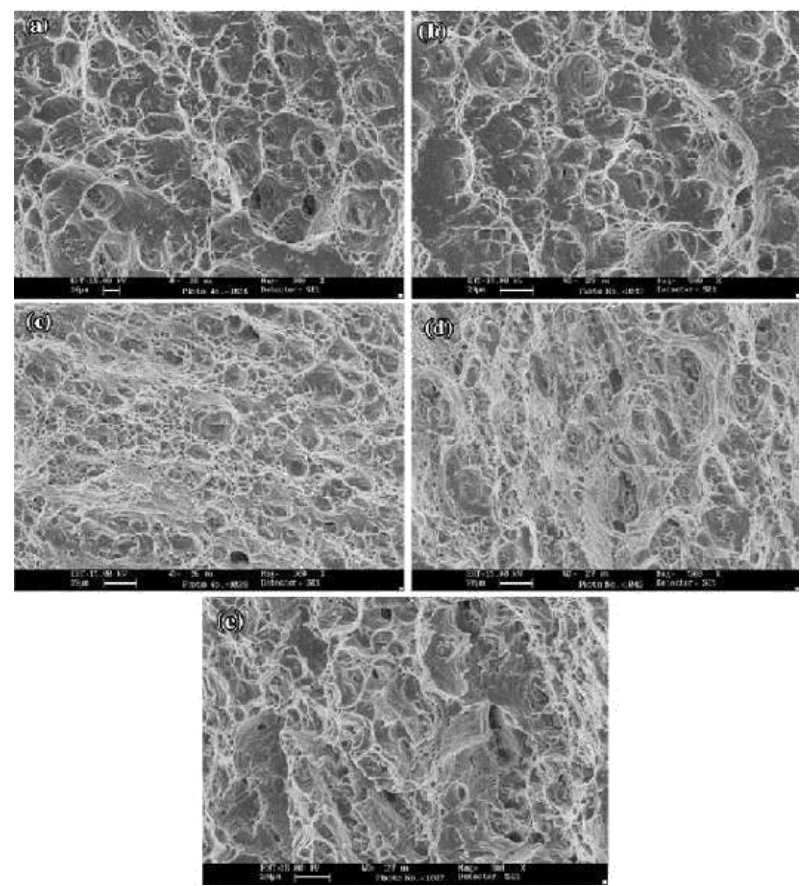

Figure 26. Fractographs of failed tensile test specimens, AA 6082-T651 FSW with different tool rotational speeds and welding speeds a) $300 \mathrm{rpm}, 15 \mathrm{~mm} / \mathrm{min}$, b) $400 \mathrm{rpm}$,

$20 \mathrm{~mm} / \mathrm{min}$, c) $500 \mathrm{rpm}, 25 \mathrm{~mm} / \mathrm{min}$, d) $600 \mathrm{rpm}, 30$ $\mathrm{mm} / \mathrm{min}$, and e) $700 \mathrm{rpm}, 35 \mathrm{~mm} / \mathrm{min}$ [63].

According to Gurney et al. [106], fatigue cracks in metals usually originate from the surface, but in the case of welded structures, cracks may be initiated from weld defects. Regions surrounding the fatigue crack initiation site usually have a very smooth appearance extending to the limit of the fatigue fracture proper. This smooth region grew progressively rougher as the fatigue crack propagated away from the nucleus. The fatigue crack initiation point can be located by careful examination of the smooth region, which is usually characterised by concentric rings (beach marking) around the fracture nuclei and the radii lines emanating from it. The direction in which the fatigue crack propagates is always perpendicular to the line of action of stresses causing it. On observing typically failed fatigue specimens, two distinct areas are identifiable namely: the fatigue area and the rupture area. If the stresses causing fatigue are low, the "area of fatigue" will be large, but if stresses are high, the area of fatigue will be low. The fracture surface of the final rupture area can be "crystalline" or "fibrous", depending on whether the fracture was brittle or ductile. Brittle failure can occur if the propagating fatigue crack is so large that the stress at the remaining section of the specimens is greater than or equal to the yield stress of the material. In this case, the surface of the final rupture region appears coarse and crystalline. The final rupture region is fibrous if the material is very ductile or the area of fatigue failure is small.

Booth and Sinclair [107] asserted that fatigue failure in FSW 2024-T351 could occur within the weld nugget or at the HAZs (i.e HAZ or TMAZ). Failure in the nugget was linked to discontinuities in the material flow pattern at the surface in the absence of obvious defects. On the other hand, TMAZ/HAZ failure was linked to de-cohesion of large S-phase particles or by transgranular failure, and this case fatigue lives were comparable to the parent material. In the same vein, Ali et al. [94] identified the flow arm zone and the TMAZ as the crack initiation zones, due to the defects induced on the surface by the tool shoulder, tensile residual stresses and oxides. Low cyclic strength, low hardness, elongated grain structure, coupled with coarse intermetallic particle distribution, favour crack propagation in the TMAZ [94]. In all these cases, crack initiation at hardness minima was not found by Bussu and Irvine [108]. Fractographs of FSW where fatigue failures initiated from roots of FSW joints as a result of root flaws and kissing bonds were shown by Zhou et al. (Figure 27) [103]. The crack propagation paths are shown in Figure 28.
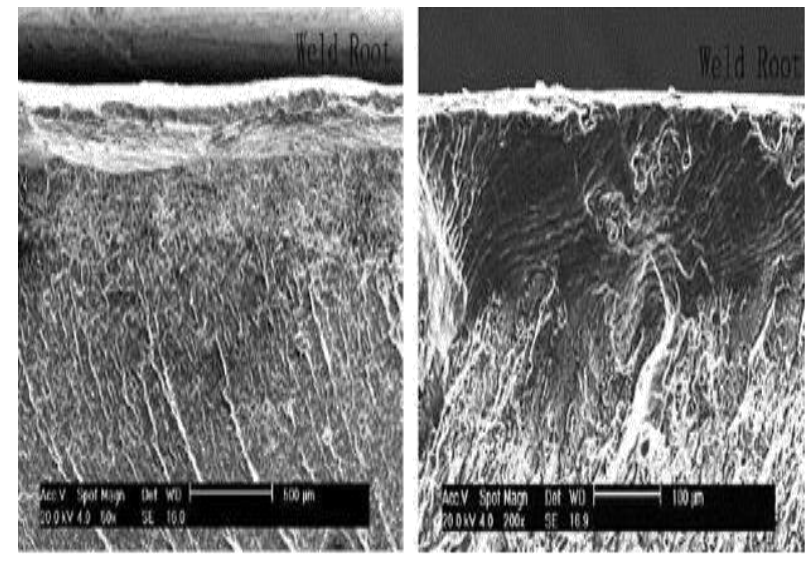

Figure 27. Fractographs of fatigued FSW samples of a) Al 5083from kissing weld and b) Al 2024 root flawed weld [103].

In Figure 28a, the schematic diagram shows the protrusions at the bottom of the Al 5083 weld which showed that cracks formed at weld root, propagated along the zig-zag line (kissing bond) and expanded from the 
kissing bond knee perpendicular to the major stress axis. On the other hand, Figure $28 \mathrm{~b}$ shows multiple crack initiation at the root region, which did not propagate along the root flaw line, but instead expanded directly normal to the stress axis [103]. This multiple initiation micro-cracks, according to Patton et al. [109] and Hornborngen et al. [110], is due to incremental accumulation of micro-plastic damage at the localised level. Zhou et al. [103] explained that under continual cyclic loading, higher stress concentration at grain boundaries led to the progressive build-up of dislocations there. Preferential plastic deformation, which led to localised stress concentration at oxide matrix interfaces, caused nucleation of microscopic cracks. These microscopic cracks coalesced and propagated through the microstructure in a direction perpendicular to the major stress axis.

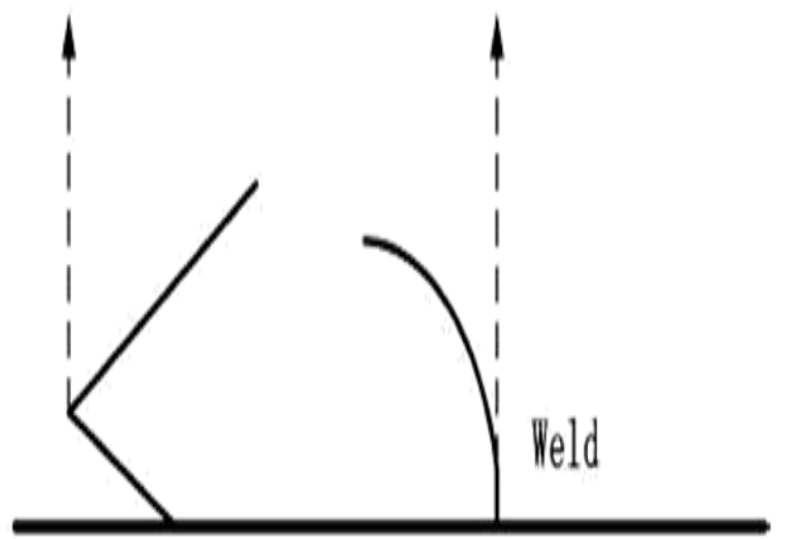
(a)
(b) Root

Figure 28. The shape of defects and fatigue crack propagation pattern in each weld, a) for Al 5083 kissing bond, and b) for Al 2024 root flawed weld [103].

In general, discontinuities such as particles, coating layers (anodizing and cladding), extrinsic features due to manufacturing processes and handlings, such as pits (from anodizing), scratches, machining marks, burrs and lack of weld penetration can be sources of the fatigue crack in space aluminium alloys [27,35,111]. Multiple nucleation sites are common-place, not only in coated aluminium alloys but also in alloys containing a high degree of discontinuities.

According to Zhou et al. [2], fatigue crack initiation and growth result from the incremental accumulation of micro-plastic damage at localized levels. The initially localized micro-plasticity is distributed randomly throughout favourably oriented grains along the entire gauge section of the test specimen. The magnitude and distribution of this localized micro-plasticity are reported to be influenced by $[2,110,112]$ :

- The magnitude of applied cyclic stress range,

- Orientation or texture of the grains,

- Stress concentrations as a result of dislocations at grain boundaries and grain/particle interface, and

- Grain boundary triple junctions (which are thought to be preferential sites for plastic deformation since they are weaker.

\section{RESIDUAL STRESS EFFECT IN FSW}

Residual stresses are the stresses retained in a stationary material which may be at equilibrium with its environment [113]. They result from manufacturing processes and their magnitudes can be as high as the yield stress [114]. Residual stresses affect the static and dynamic properties, chemical resistance, and the magnetization of metallic materials [115]. Failure in structures is not only caused by the applied stresses but also by residual stresses. They can make the material intolerant of externally applied stresses, particularly when stress concentrators such as weld toes, defects, and cracks are present [113,114]. Also, residual stresses limit the life of thin films and coatings meant for corrosion prevention by causing cracks and spalling [113]. In engineering structures, macro-residual stresses may develop as a result of misfits between interacting parts, which could have been induced chemically, plastically, or thermally. In welded structures, large thermal stress gradients are caused in the weld zone by localized heating and cooling, induce residual stresses [113].

Residual stresses, although lower in FSW compared to conventional welding processes, affect both the fatigue crack initiation and growth processes, and other post-weld mechanical properties [108,114]. Crack growth behaviour is thought [108] to be dominated by weld residual stress, and microstructure has only a small influence. Compressive residual stresses are beneficial [10,116], while tensile residual stresses negatively affect mechanical properties, causing crack initiation and propagation, leading to catastrophic failure [10]. This is because tensile stresses add to the applied stress and failure occurs at lower loads than expected [114]. In FSW, as with other conventional welding techniques, residual stresses are developed as a result of expansion during 
heating and contraction during cooling. FSW welding parameters such as welding and rotational speed are also principal contributing factors, in addition to the mechanical constraint on the plates by clamps and fixtures, as shown by Chen and Kovasevic [117] through FEA of clamped FSW 6061Al. They have shown that increased rotational speed decreased lateral and longitudinal residual stresses, while a higher welding speed increased longitudinal residual stresses, but reduced lateral stresses. When FSW samples were unclamped, the residual stress distribution is altered. With the fixtures in position, lateral stress was greater than longitudinal stress, both of which were tensile in condition. As soon as the fixtures were removed, both decreased significantly, and at $20 \mathrm{~mm}$ and $45 \mathrm{~mm}$ from the weld centerline, longitudinal stress had compressive values.

\section{MATERIAL FLOW IN FSW}

Material flow in FSW can be viewed as a combination of extrusion and forging [10]. The onion ring structure observed in the microstructure of the FSW nugget is the intersection of successive circular revolutions, and indicative of the mode of material transport produced by the tool rotation [70]. Movement of material occurs more at the retreating side than the advancing side. This is because of the rotation direction of the tool on this side as opposed to the transverse direction, hence the material moves backward in reaction to both forward transverse forces and also in response to backward rotational forces. Overall transport of the plasticized material and joint formation results from three modes of flow, namely [10]:

- Rotational motion of a slug of material around the tool, which is also known as "recirculating plastic flow",

- The downward motion of the material as a result of the rotational motion of thread tool pin which in response moves an equivalent volume of materials upwards, and

- The relative motion of the tool and material of the workpiece.

The maximum mass and velocity of recirculating materials flow is found in the flow arm zone (above the weld nugget), which is above the weld nugget because this region receives additional torque from the tool shoulder [10]. The velocity of these re-circulating materials reduces with depth, as illustrated in Figure 29.
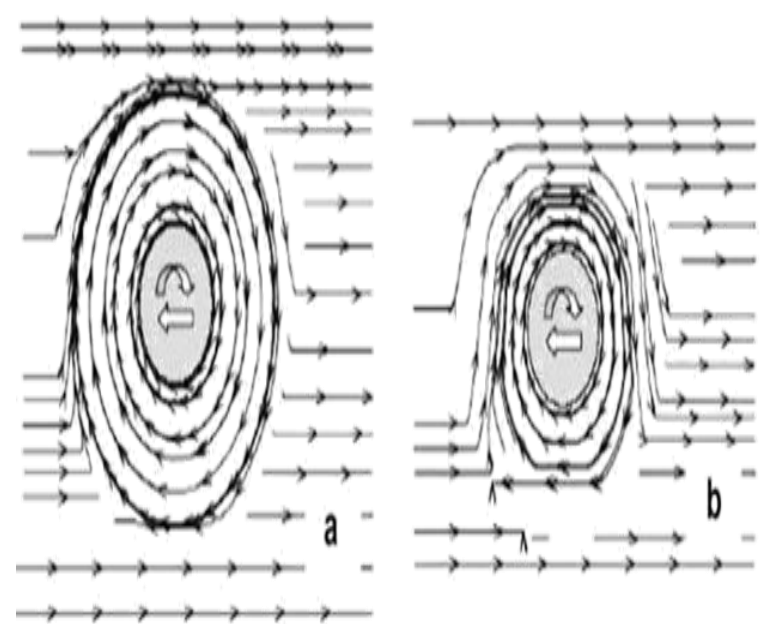

Figure 29. Material flow traces at different elevations of the tool pin: (a.) just below the shoulder, (b) half the height of the pin, and (c) near the tip of the pin $[10,118]$.

Vertical mixing of the material in the weld nugget is reported [10] to be dependent on the weld pitch (welding speed/rotational speed) and threading on the rotating tool. The material which is heated and stirred by the shoulder and pin is moved circularly downwards from the top to the bottom of the weld nugget by the tool thread [10]. This was confirmed by a stop-action technique applied by Colligan et al. [119] to study FSW by suddenly stopping the welding and un-plunging the tool. Vertical striations were seen at the bottom portion, while horizontal striations were seen close to the shoulder. Investigations of material flow using a tracer by Schmidt et al. [120] estimated the average velocity of material to be $0.1-0.3$ times the shoulder speed. Parallel copper markers perpendicular to weld centerline were used to qualitatively characterize material flow by Reynolds [121], and the complexity of material flow was dependent on weld pitch and tool design, because small weld pitch gave rise to continuous 
welds signifying better weld, and conical tools led to welds with fewer defects [121,122].

The onion ring structure, which is a product of material flow, is dependent on both welding parameters and base material microstructure $[10,121]$. Successive bands of this onion the structure has been shown to contain different densities of second phase particles, which invariably affect the local mechanical properties indicated by microhardness $[10,66,123,124]$. Booth et al. [124] deduced that the presence of particles in bands fragmented by the fast rotating tool resulted in different quench sensitivities, hence the difference in microhardness. Cracks growing into the weld changed direction as they approached the onion ring structure [10,107,124,125].

Material torque around the tool is governed by applied vertical pressure, tool design, the tilt angle, local shear stress at the tool material interface, the friction coefficient, and the extent of slip between the tool and the material [10]. Torque decreases as the tool rotation decreases because of the resultant reduction in heat generation.

\section{FSW TOOL DESIGN}

Tool design influences the heat generated in the weld, the material flow, power required and uniformity of welded joint [6,88], and also microstructure and mechanical properties [88]. Greater material flow and heat were obtained at the crown of the weld, due to the supplementary motion provided by the shoulder [10].

FSW tool design is characterized by the following parameters:

- Shoulder diameter: Excessively wide tool diameter can sweep surface oxide into the weld resulting in entrapped oxide defects [126].

- Pin diameter: The volume of material stirred during FSW is proportional to the diameter of the tool pin [65].

- Pin length [1].

- Pin shape: Cylindrical and tapered tool pins are common but are not effective in avoiding weld defects such as worm-holes [10,127].

- Pin angle: Pin angle is the angle between the conical surface of the pin and its axis. Increasing pin angle leads to more uniform temperature distribution along the vertical direction and may help reduce distortion $[10,128]$.

- Pin threading: Threaded tools generate more heat and improve the vertical mixing of the material because they exert higher downward forces in comparison with unthread cylindrical and tapered tools [10,129,130].
Table 2 gives an overview of tools designed by TWI. Their features are described in Section 2.13.2.

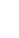




\author{
Acta Materialia Turcica \\ Volume 4, October 2020, Pages 1-39
}

Table 2. Selection of tools designed at TWI $[1,10,131]$.

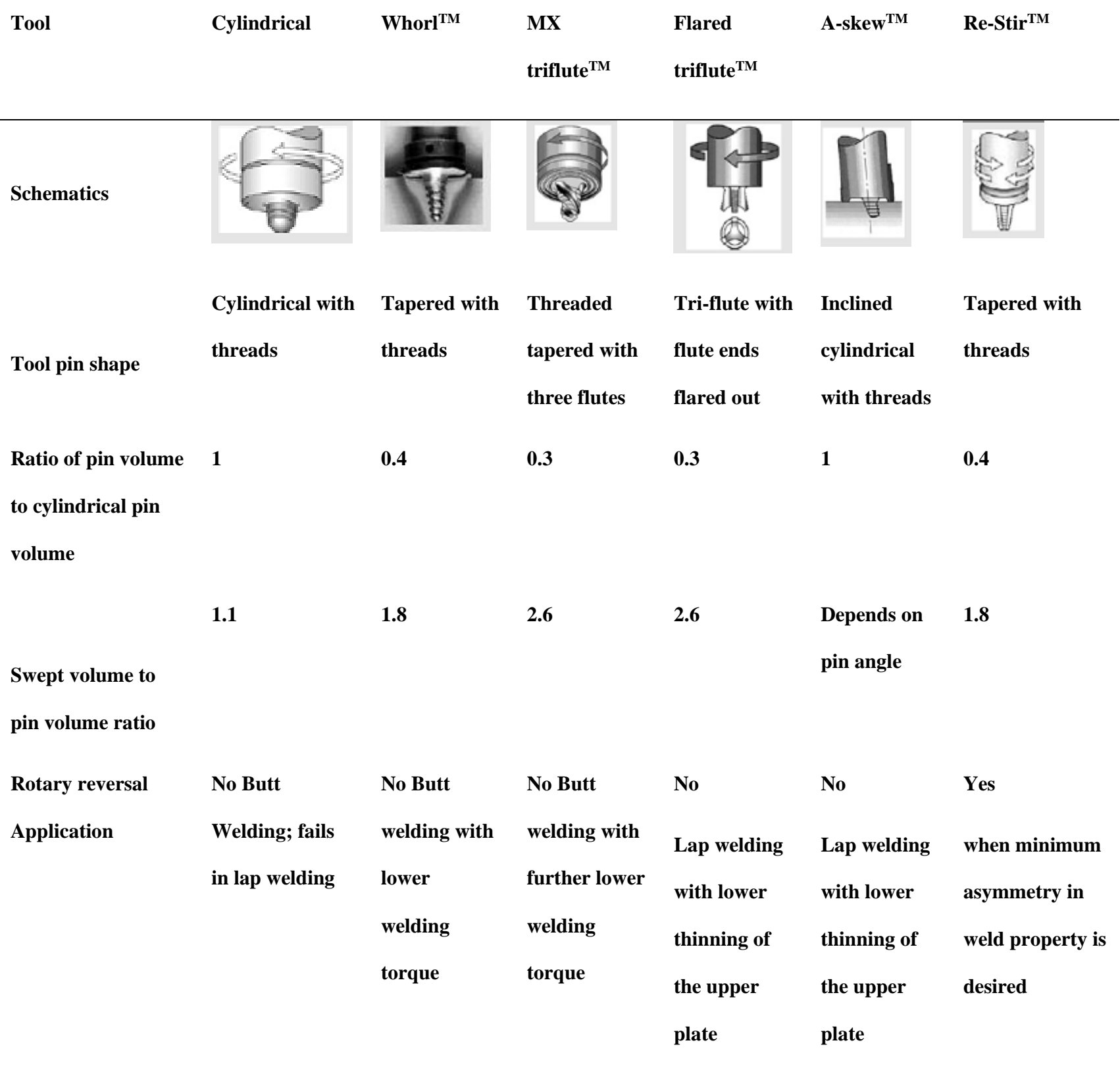




\section{DEFECTS AND DEFECTS DETECTION IN FSW}

Defects in welded joints lead to lower tensile and fatigue strengths [30,132-134], which may have serious implications where welded components are proposed for application in structures (like airframes). Here, failure is of grave concern because of safety [29]. Poorly selected tool design and operation parameters may be responsible for the nature of defects in FSW. The following defects have been observed in friction stir welds:

- Pinholes,

- Voids,

- Joint line remnant,

- Joint mismatch, and

- Incomplete root penetration.

\subsection{VOIDS AND PIN HOLES}

Voids in FSW components cannot be easily be detected by non-destructive testing such as visual inspection, liquid penetrant methods, multiple ultrasonic methods, and eddy current and conductivity methods [135]. They are mostly found in the advancing side of the weld (Figure 31), and may penetrate to the surface, but may also be formed in the weld nugget or retreating side, depending on the extent of deviation from the operating process window $[6,136,137]$. The void formation is due to insufficient forging pressure, too high welding speed, and insufficient workpiece clamping (too large a joint gap) for selected tool design. Material deformed by the friction stir tool must be able to fill the void produced by a traversing pin. If the tool design is incorrect (i.e. pin diameter is too large for the selected welding setup) or the travel speed too fast, the deformed material will cool before the material can fill the region directly behind the tool. Also, the shoulder must apply sufficient heat generation to allow the material to flow around the tool; if insufficient heat is generated (through insufficient forging pressure or incorrect shoulder diameter), then the material will not flow properly, and voids will form [1]. From a material flow model [10], minimal material flow around the rotating pin at lower horizontal planes during welding is responsible for wormhole defects. By contrast, Singh et al. [63] and Elangovan et al. [97] showed that higher tool rotational speed gave an excessive release of stirred material from lower to upper surfaces, which resulted in the formation of microvoids in the lower part of the stirred zone and a decrease in tensile strength. The presence of pinholes adversely affected the mechanical properties of FSW components, for example, Barcellona et al.[73] found that microscopic pinholes led to lower UTS values, even after PWHT.

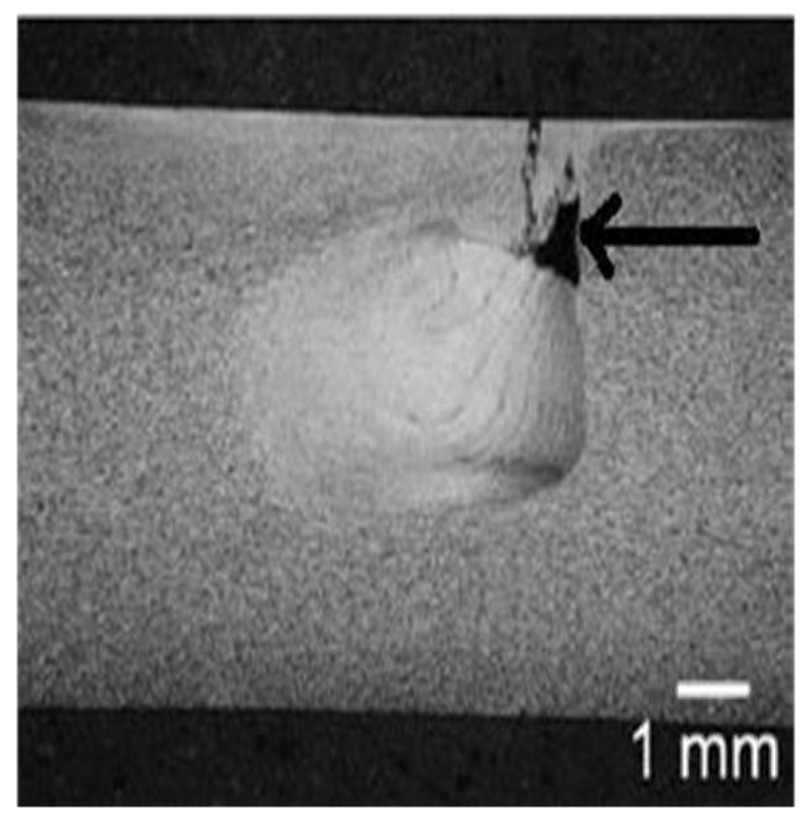

Figure 30. Macrograph of FSW nugget showing voids [1].

\subsection{JOINT LINE REMNANTS}

Joint line remnants are formed from the oxide film on the surface of the workpiece which forms sub-continuous layers in the weld nugget. They are also known as 'kissing bonds', 'zig-zag lines' 'lazy-Ss', 'entrapped oxide defects', or 'swirl zones (SWZ)' [103,138]. They could result from insufficient cleaning of workpieces before welding, or insufficient deformation at the faying surface interface due to incorrect tool location relative to the joint line, too fast welding speed, or too large tool shoulder diameter. They comprise an array of oxides (Figure 32) that cannot be detected by ultrasonic and dye penetrant methods [86]. These oxides, which were originally on the surface, were broken down, dispersed, and pushed by the rotating tool into the weld. Depending on the revolution pitch, oxides could appear as onion-like or weave-like patterns. According to Okamura et al. [139], within the normal range of defect-free joining conditions, entrapped 


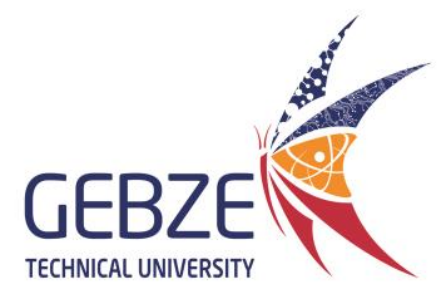

Acta Materialia Turcica

Volume 4, October 2020, Pages 1-39

oxides should have no adverse effect on the tensile strength of FSW joints.

Kahl and Soren [71] discovered weak and strong bands of oxides in different FSW samples, which had no impact on their mechanical properties. Similarly, others have observed that the band of alumina may lead to low heat generation during welding [139], resulting in a zig-zag line in the weld nugget [139]. However, alumina bands did not affect the root bend property of the weld [140], nor impact negatively on the tensile strength or offset yield strength when they initiated tensile fracture [141]. Conversely, kissing bonds can reduce the fatigue crack initiation life, and hence fatigue life of FS welds in both low-cycle and high-cycle regimes, especially in the former, as proven by Zhou et al. [103]. The nature and size of the swirl zone (SWZ) observed by Attallah et al.[138] was quite different from the others and appeared as dark patterns (Figure 33) at the lower side of the TMAZ after etching. The cause is thought to be that thermally induced surface oxide seeped from the abutting edges of the workpieces during welding [138]. The oxide bands were dependent on welding parameters [138].
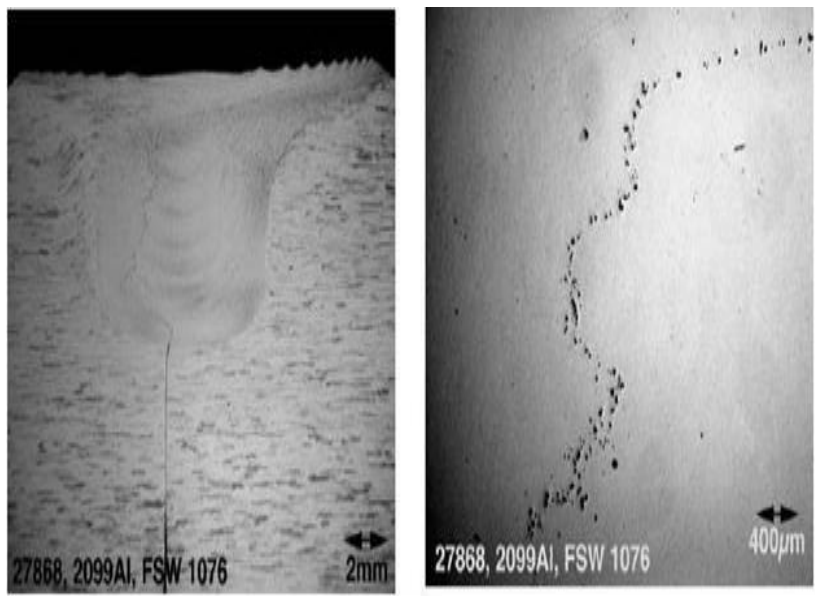

Figure 31. a) Micrograph showing joint line remnant, and b) Magnification showing oxide debris that caused the joint line remnant [1].

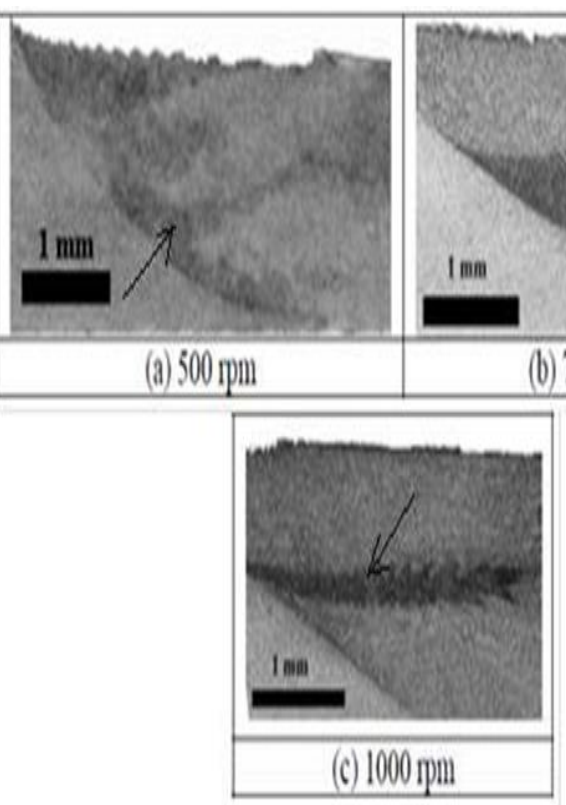

Figure 32. Nature of swirl zone (shown by arrows) with different rotational speeds [138].

\subsection{JOINT MISMATCH}

The joint mismatch occurs when one of the abutting edges is displaced vertically and/or horizontally under the action of the stirring tool, as shown in Figure 34. This is as a result of inadequate or loose clamping of the abutting workpieces before welding.

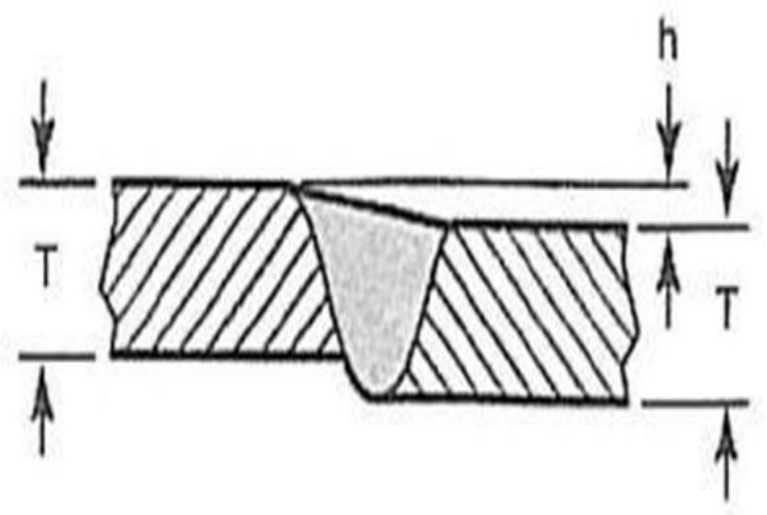

Figure 33. Schematic diagram of mismatch in FSW [142]. 


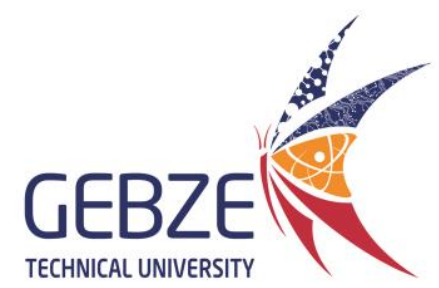

Acta Materialia Turcica

Volume 4, October 2020, Pages 1-39

\subsection{WELD FLASH AND SURFACE ROUGHNESS}

Weld flash and surface roughness occur when the plunge depth is too high or the shoulder diameter is too low, as shown in Figure 34. These defects are not easily avoided in force-controlled welding since the tool does not stop plunging into the workpiece until the required downward force is obtained. On the other hand, position-controlled FSW makes it possible to limit weld flash, but an inadequate downward force may result in weld defects.

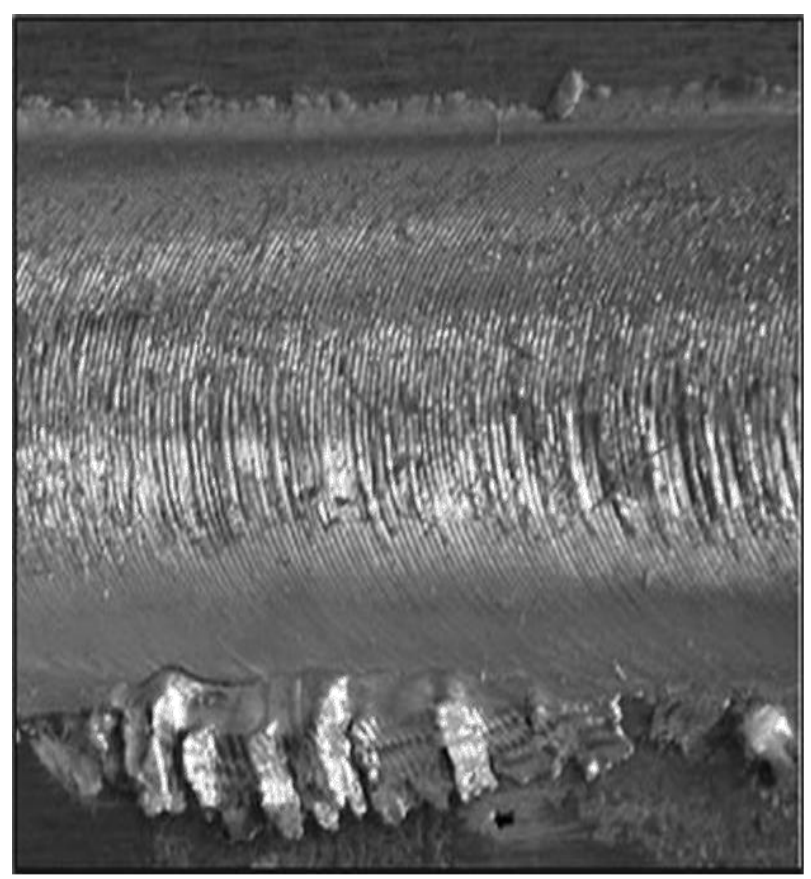

Figure 34. Weld flash as a result of high vertical force, or differential in weld thickness to the base material [143].

\subsection{INCOMPLETE ROOT PENETRATION}

Incomplete root penetration is also known as the root flaw or lack of penetration (LOP). Several factors are responsible, including local variations in the plate thickness, poor alignment of the tool relative to the joint interface, and improper tool orientation and low heat input [30]. TEM studies [140] have shown a high density of fine Al2O3 particles $(<100 \mu \mathrm{m})$, with an amorphous structure, mostly located on grain boundaries, which caused preferentially etched lines, observed in a light microscope as shown in Figure 35a.
Incomplete root penetration occurs when the FSW pin is too distant from the supporting anvil. Thus, an undeformed region exists between the bottom of the tool and the bottom surface of the plate. When subjected to bending stress, the friction stir weld will fail along with the lack of penetration line, as shown in Figure 35b. Flawless welding of butting edges requires a sufficient depth of deformation (either through pin length or design) to eliminate the incomplete root penetration, while ensuring that the pin will not touch the backing anvil [1]. Peel et al. [144] suggested that FSW could be optimized, and lower transverse speed and wider coarser tool pin could eliminate oxide arrays that exist both as root flaws or kissing bonds. Experiments conducted on FSW 2024 by Zhou et al. [103] proved that root flaws could reduce fatigue life (by 30-80 times shorter), in low and high cycle regimes, especially in the latter.
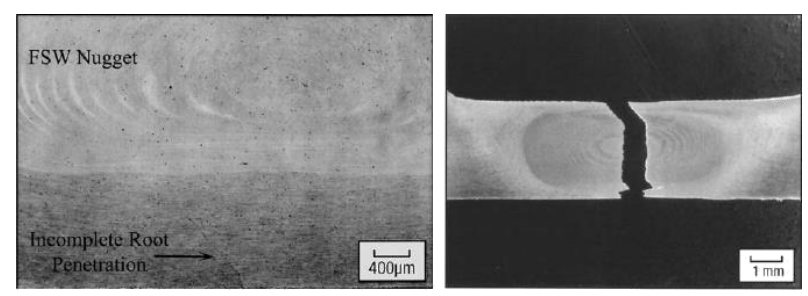

Figure 35. Macrograph showing a. incomplete root penetration, and $\mathrm{b}$. fracture path dictated by incomplete root penetration [1].

\section{ADVANCES IN FSW}

FSW was originally developed for joining aluminum alloys but has been extended to higher melting point materials such as steels, and copper, as well as polymeric materials $[10,145]$. It is a relatively new and rapidly evolving process with over 1500 subsidiary patents and 135 licensees. Major advances in tool design, process, and applications have been recorded [146].

\section{REFERENCES}

[1] R. S. Mishra, M. W. Mahoney, Friction stir welding and processing, ASM International, 2007.

[2] C. Zhou, X. Yang, G. Luan, Investigation of microstructures and fatigue properties of friction stir welded Al-Mg alloy, Mater. Chem. Phys. 98 (2006) 285290.

DOI:

https://doi.org/10.1016/j.matchemphys.2005.09.019 
[3] M. Ericsson, R. Sandstrom, Influence of welding speed on the fatigue of friction stir welds, and comparison with MIG and TIG, Int. J. Fatigue, 25 (2003) 1379-1387.

DOI: https://doi.org/10.1016/S0142-1123(03)00059-8

[4] C. Chen, R. Kovacevic, Joining of Al 6061 alloy to AISI 1018 steel by combined effects of fusion and solid state welding, Int. J. Mach. Tools Manuf., 44 (2004) 1205-1214.

DOI: https://doi.org/10.1016/j.ijmachtools.2004.03.011

[5] W.B. Lee, M. Schmuecker, U. A. Mercardo, G. Biallas, S.B. Jung, Interfacial reaction in steel-aluminum joints made by friction stir welding, Scr. Mater., 55 (2006) 355-358.

DOI: https://doi.org/10.1016/j.scriptamat.2006.04.028

[6] R. S. Mishra, Z. Y. Ma, Friction stir welding and processing, Mater. Sci. Eng. R Reports, Friction stir welding and processing. 50, (2005), 1-78.

DOI: https://doi.org/10.1016/j.mser.2005.07.001

[7] M. Pacchione, J. Telgkamp, Challenges of the metallic fuselage, Proceedings of the 25th International Congress of the Aeronautical Sciences-ICAS, 451 (2006) 1-45.

[8] A. Lanciotti, C. Polese, Impact of direct water cooling on the quality and performance of friction stir welded joints in a $\mathrm{AlMgSiCu}$ aluminium alloy, University of Witwatersrand, Johanesburg, 2004.

[9] H. Kafali, and N. Ay, Mechanical properties of 6013T6 Aluminium alloy friction stir welded plate, Proceedings of the 13th International Conference on Aerospace Sciences and Aviation Technology, Paper ASAT-13-MS-14, May 26-28, 2009.

[10] R. Nandan, T. Debroy, H. Bhadeshia, Recent advances in friction-stir welding - process, weldment structure and properties, Prog. Mater. Sci., 53 (2008), 980-1023.

DOI: https://doi.org/10.1016/j.pmatsci.2008.05.001

[11] H. WEBSTER, About FSW, http://hfwebster.com/about-hfw/about-fsw, 2020.

[12] W. M. U. Thomas, E. D. Nicholas, A. Hall, C. Cb, Friction stir welding for the transportation industries, Mater. Des., 18 (1998), 269-273.
DOI: https://doi.org/10.1016/S0261-3069(97)00062-9

[13] T. Akinlabi, PhD Thesis, Nelson Mandela Metropolitan University (NMMU), 2010.

[14] C. Genevois, A. Deschamps, A. Denquin, B. Doisneaucottignies, Quantitative investigation of precipitation and mechanical behaviour for AA2024 friction stir welds, Acta Mater., 53, (2005) 2447-2458. DOI: https://doi.org/10.1016/j.actamat.2005.02.007

[15] Y. S. Sato, M. Urata and H. Kokawa, Parameters controlling microstructure and hardness during frictionstir welding of precipitation-hardenable aluminum alloy 6063, Metall. Mater. Trans. A, 33 (2002) 625-635.

DOI: https://doi.org/10.1007/s11661-002-0124-3

[16] Y. S. Sato, H. Kokawa, M. Enomoto, S. Jogan, Microstructural evolution of 6063 aluminum during friction-stir welding, Metall. Mater. Trans. A, 30 (1999) 2429-2437.

DOI: https://doi.org/10.1007/s11661-999-0251-1

[17] Y. S. Sato, Relationship between mechanical properties and microstructure in friction stir welded $\mathrm{Al}$ alloys, Weld. Int., 17 (2003) 706-709.

[18] M. Jones, P. Heurtier, C. Desrayaud, F. Montheillet, D. Allehaux, J. Driver, Correlation between microstructure and microhardness in a friction stir welded 2024 aluminium alloy, Scr. Mater., 52 (2005) 693-697.

DOI: https://doi.org/10.1016/j.scriptamat.2004.12.027

[19] J. Q. Su, T. W. Nelson, R. Mishra, M. Mahoney, Acta Mater., 2003, 51, 713-729.

[20] M. Mahoney, C. Rhodes, J. Flintoff, Properties of friction-stir-welded 7075 T651 aluminum, Metall. Mater.

Trans. A, 29 (1998) 1955-1964.

DOI: https://doi.org/10.1007/s11661-998-0021-5

[21] C. G. Rhodes, M. W. Mahoney, W. H. Bingel, R. A. Spurling, C. Bampton, Effects of Friction Stir Welding on microstructure of 7075 aluminium, Scr. Mater., 1997, 36, 69-75.

DOI: https://doi.org/10.1016/S1359-6462(96)00344-2

[22] O. J. Dada, C. Polese, L. A. Cornish, B. O. Adewuyi, J. O. Borode, Characterisation of innovative friction stir welding joints for airframe structures: research overview 
African Materials Science and Engineering Network (AMSEN) Worshop, Nairobi, March 21-23, 2012.

[23] H. Hori, S. Makita, H. Hino, Proceedings of the First International Symposium on Friction Stir Welding, Thousand Oaks, CA, USA, June 14-16, 1999.

[24] M. P. Miles, T. W. Nelson, B. J. Decker, Formability and strength of friction-stir-welded aluminum sheets Metal. Mater. Trans. A, 35 (2004) 3461- 3468.

DOI: https://doi.org/10.1007/s11661-004-0183-8

[25] H. G. Salem, A. P. Reynolds, J. S. Lyons, Microstructure and retention of superplasticity of friction stir welded superplastic 2095 sheet, Scr. Mater., 46 (2002) 337-342.

DOI: https://doi.org/10.1016/S1359-6462(01)01246-5

[26] Y. J. Chao, X. Qi, W. Tang, Heat transfer in friction stir welding-experimental and numerical studies, J. Manuf. Sci. Eng., 125 (2003) 138.

[27] T. Okada, M. Suzuki, H. Miyake, T. Nakamura, S. Machida, M. Asakawa, Evaluation of crack nucleation site and mechanical properties for friction stir welded butt joint in 2024-T3 aluminum alloy, Int. J. Adv. Manuf. Technol., 50 (2010), 127-135.

DOI: https://doi.org/10.1007/s00170-009-2513-x

[28] B. Boen, NASA - A Bonding Experience: NASA Strengthens Welds, http://www.nasa.gov/topics/nasalife/friction_stir.html, 2012.

[29] B. R. Somers, A. W. Pense, Welding failure analysis, Mater. Charact., 33, (1994) 295-309.

DOI: https://doi.org/10.1016/1044-5803(94)90049-3

[30] S. Lomolino, R. Tovo, J. Dossantos, On the fatigue behaviour and design curves of friction stir butt-welded Al alloys, Int. J. Fatigue, 27 (2005), 305-316.

DOI: https://doi.org/10.1016/j.ijfatigue.2004.06.013

[31] ESAB, Technical Hand Book: Friction Stir Welding, http://www.esab.com/global/en/education/techinfo-friction-stir-welding.cfm, accessed 4 June 2012.

[32] A. Heinz, A. Haszler, C. Keidel, S. Moldenhauer, R. Benedictus, W. Miller, Recent Development in
Aluminium Alloys for Aerospace Applications, Mater. Sci. Eng. A, 280 (2000) 102-107. DOI: https://doi.org/10.1016/S0921-5093(99)00674-7

[33] G. Tempus, Werkstoffe für transport und verkehr, ETH Zurich, 2001.

[34] G. Pouget, A. P. Reynolds, Residual stress and microstructure effects on fatigue crack growth in AA2050 friction stir welds, Int. J. Fatigue, 30 (2008) 463-472. DOI: https://doi.org/10.1016/j.ijfatigue.2007.04.016

[35] A. Merati, Materials replacement for aging aircraft, Corrosion Fatigue and Environmentally Assisted Cracking in Aging Military Vehicles, (2011) 24.1-24.22.

[36] J. M. Goetz, The Ohio State University, Columbus, OH, USA, 2005.

[37] J. Kaufman, Properties of aluminum alloys: fatigue data and the effects of temperature, product form, and processing, ASM International, 2008.

[38] C. Zhou, X. Yang, G. Luan, Effect of root flaws on the fatigue property of friction stir welds in 2024-T3 aluminum alloys, Mater. Sci. Eng. A, 418 (2006) 155-160. DOI: https://doi.org/10.1016/j.msea.2005.11.042

[39] T. Dickerson, J. Przydatek, Fatigue of friction stir welds in aluminium alloys that contain root flaws, Int. J.

Fatigue, 25 (2003) 1399-1409.

DOI: https://doi.org/10.1016/S0142-1123(03)00060-4

[40] S. W. Williams, Welding of airframes using friction stir, Air Sp. Eur. Aircr. Technol., 3 (2001) 64-66.

[41] M. M. Ratwani, RTO AVT lecture series on ageing aircraft fleets: structural and other subsystem aspects, 2000.

[42] D. Burford, C. Widener, Advances in friction stir welding for aerospace applications, http://www.niar.wichita.edu/media/pdf/nationalpublicatio n/Nov2-06.pdf, 2012.

[43] K. Dimitris, Aluminium structures fatigue design concepts and tools in AlFat Ec9 Brussels (2008) 1-8. 
[44] Aero Index UK, Aicraft structures design, [55] J.K. Paik, Mechanical properties of friction stir http://www.aviationdatabase.com/aviation_database_pages1/Aicraftwelded aluminum alloys 5083 and 5383, Int. J. Nav. Archit. Ocean Eng., 1 (2009) 39-49. structures-design.html, 2012.

DOI: https://doi.org/10.2478/IJNAOE-2013-0005

[45] J. Telgkamp, H. J. Schmidt, Structural health monitoring 2003: From Diagnostics

\& Prognostics to Structural Health Management Proceedings of the 4th International

Workshop on Structural Health Monitoring, Stanford University, Stanford, CA, September 15-17, 2003.

[46] M. Neubauer, G. Günther, Aircraft Loads, RTP AVT Lecture Series, April 2012.

[56] D. Rao, J. Heerens, G. Alves Pinheiro, J. F. dos Santos, N. Huber, On characterisation of local stressstrain properties in friction stir welded aluminium AA 5083 sheets using micro-tensile specimen testing and instrumented indentation technique, Mater. Sci. Eng. A, 527 (2010) 5018-5025.

DOI: https://doi.org/10.1016/j.msea.2010.04.047

[47] Aviation Metals INC, Inroduction to Aluminium Alloys, www.aviationmetals.net/aluminum_sheet.php, accessed 14 March 2012.

[48] G. Mathers, The welding of aluminium and its alloys, Woodhead Publishing Limited, 2002.

[57] P. Vilaça, N. Pepe, L. Quintino, Metallurgical and Corrosion Features of Friction Stir Welding of AA5083H111, J. Int. Inst. Weld., 50 (2006) 55-64.

[58] Alcoa, Alcoa mill products alloy 2024 sheet and plate excellent fatigue properties - consistent performance, https://www.academia.edu/30694831/ALLOY_2024_SH EET_AND_PLATE_EXCELLENT_FATIGUE_PROPE

[49] J. E. Hatch, Aluminum: Properties and Physical Metallurgy, ASM International, 1984.

RTIES_CONSISTENT_PERFORMANCE, accessed July 2020.

[59] Alcoa, Alloy 6061 understanding extruded

[50] S. T. Amancio-Filho, S. Sheikhi, J. F. dos Santos, C. Bolfarini, Preliminary study on the microstructure and mechanical properties of dissimilar friction stir welds in aircraft aluminium alloys 2024-T351 and 6056-T4, J. Mater. Process. Technol., 206 (2008) 132-142.

DOI: https://doi.org/10.1016/j.jmatprotec.2007.12.008

[51] Aalco Metals Ltd, Aluminium Alloy - Commercial Alloy - $6082 \quad-\quad$ T6 T651, http://www.aalco.co.uk/datasheets/Aluminium-

Aluminum alloys,

https://www.yumpu.com/en/document/view/11671878/al loy-6061-understanding-extruded-aluminum-alloys,

Accessed July 2020

[60] Alcoa mill product inc, Alcoa mill products alloy 6013 sheet higher strength with improved formability, www.millproducts-alcoa.com, March 2012.

[61] K. H. Hassan, P. B. Prangnell, A. F. Norman, D. A. Alloy_6082-T6 T651_148.ashx, Accessed June 2020.

[52] J. G. Kaufman, A. S. M. International, Introduction to aluminum alloys and tempers, ASM International, 2000.

Price, S. W., Williams, Effect of welding parameters on nugget zone microstructure and properties in high strength aluminium alloy friction stir welds, Sci. Technol. Weld. Join., 8 (2003) 257-268(12).

DOI: https://doi.org/10.1179/136217103225005480

[53] Z. Barlas, U. Ozsarac, Effects of FSW parameters on joint properties of $\mathrm{AlMg}_{3}$ alloy. Weld. J., 91 (2012) 1622.

[62] S. R. Ren, Z. Y. Ma, L. Q. Chen, Effect of welding parameters on tensile properties and fracture behavior of friction stir welded $\mathrm{Al}-\mathrm{Mg}-\mathrm{Si}$ alloy, Scr. Mater., 56 (2007), 69-72.

[54] I. J. Polmear, Light alloys: metallurgy of the light metals, J. Wiley \& Sons, 1995.

DOI: https://doi.org/10.1016/j.scriptamat.2006.08.054

[63] G. Singh, K. Singh, J. Singh, Effect of process parameters on microstructure and mechanical properties 
in friction stir welding of aluminum alloy, Trans. Indian Inst. Met., 64 (2011) 325-330.

DOI: https://doi.org/10.1016/j.jma.2016.11.005

[64] R. M. Indira, R. N. Marpu, A. C. Kumar, A study of process parameters of friction stir welded AA6061 aluminum alloy in $\mathrm{O}$ and T6 conditions, ARPN J. Eng. Appl. Sci., (2011) 6, 61-66.

[65] S. Rajakumar, C. Muralidharan V. Balasubramanian, Optimization of the friction-stir-welding process and tool parameters to attain a maximum tensile strength of AA7075-T 6 aluminium alloy, Proc. Inst. Mech. Eng. Part B J. Eng. Manuf. 224 (2010) 1175-1191.

DOI: https://doi.org/10.1243/09544054JEM1802

[66] J. Yan, M. Sutton, A. Reynolds, A Process-structureproperty relationships for nugget and heat affected zone regions of AA2524-T351 friction stir welds, Welds, Sci. Technol. Weld. Joining, 10 (2005), 725- 736.

DOI: https://doi.org/10.1179/174329305X68778

[67] A. K. Hussain, Evaluation of parameters of friction stir welding for aluminium AA6351 alloy, Int. J. Sci. Technol., 2 (2010) 5977-5984.

[68] P. Cavaliere, A. De Santis, F. Panella, A. Squillace, Effect of welding parameters on mechanical and microstructural properties of dissimilar AA6082-AA2024 joints produced by friction stir welding, Mater. Des., 30, (2009) 609-616.

DOI: https://doi.org/10.1016/j.matdes.2008.05.044

[69] D. Trimble, J. Monaghan, G. O’Donnell, Force generation during friction stir welding of AA2024-T3, CIRP Ann. 61 (2012), 9-12.

DOI: https://doi.org/10.1016/j.cirp.2012.03.024

[70] T. S. Srivatsan, S. Vasudevan, L. Park, The tensile deformation and fracture behavior of friction stir welded aluminum alloy 2024, Mater. Sci. Eng. A, 466, (2007) 235-245.

DOI: https://doi.org/10.1016/j.msea.2007.02.100

[71] S. Kahl, Fatigue strength of friction stir welds in aluminium alloy AA6082-T6, 8th International Symposium on Friction Stir Welding, Timmendorfer Strand, Germany 18-20 May, 2010.

Corresponding Author E-mail: oluwaseunjohndada@tdtu.edu.vn
[72] C. G. Derry, J. D. Robson, Characterisation and modelling of toughness in 6013-T6 aerospace aluminium alloy friction stir welds. Mater. Sci. Eng. A, 490 (2008), 328-334.

DOI: https://doi.org/10.1016/j.msea.2008.01.044

[73] A. Barcellona, G. Buffa, L. Fratini, D. Palmeri, On microstructural phenomena occurring in friction stir welding of aluminium alloys. J. Mater. Process. Technol., 177 (2006), 340-343.

DOI: https://doi.org/10.1016/j.jmatprotec.2006.03.192

[74] G. Biallas, R. Braun, C. D. Donne, G. Staniek, W. A. Kaysser, Mechanical properties and corrosion behavior of friction stir welded 2024-T3, Proc. First Int. Conf. Frict. Stir Weld., 2-11, 1999.

[75] A. Von Strombeck, J. dos Santos, F. Torster, P. Laureano, M. Kocak, Fracture toughness behavior of fsw joints on aluminum alloys, First International Symposium on Friction Stir Welding, June 1999 (Thousand Oaks, CA), TWI, 1999.

[76] L. Magnusson, L. Kallman, Mechanical properties of friction stir welds in thin sheet of aluminium 2024, 6013 and 7475 , Second International Symposium on Friction Stir Welding, (Gothenburg, Sweden), June 26-28, 2000.

[77] D. Lohwasser, Application of friction stir welding for aircraft industry, Second International Symposium on Friction Stir Welding, Gothenburg, Sweden, TWI, June 26-28, 2000.

[78] G. Bussu, P. E. Irving, Fatigue performance of friction stir welded 2024-T351, First International Symposium on Friction Stir Welding, (Thousand Oaks, CA), TWI, 1999.

[79] J. Kristensen, C. Dalle Donne, T. Ghidini, J. Mononen, A. Norman, A. Pietras, M. Russell, S. Slater, Properties of Friction Stir Welded Joints in Aluminum Alloys 2024, 5083, 6082/6060 and 7075, Fifth Int. Friction Stir Welding Conference, Metz, France, TWI,1416, September 2004.

[80] B. Christner, J. McCoury, S. Higgins, Development and testing of friction stir welding (fsw) as a joining method for primary aircraft structure, International 


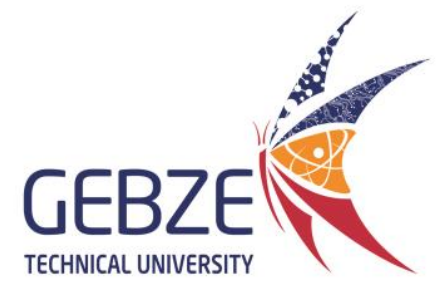

Acta Materialia Turcica

Volume 4, October 2020, Pages 1-39

Symposium on Friction Stir Welding, (Park City, UT), TWI, May 14-16, 2003.

[81] C. Dalle Donne, G. Biallas, T. Ghidini, G. Raimbeaux, Effect of weld imperfections and residual stresses on the fatigue crack propagation in friction stir welded joints, Second Int. Symp. Frict. Stir Welding, (Gothenburg, Sweden), TWI, June 26-28, 2000.

[82] L. Karlsson, L. Svensson, H. Larsson, Characteristics of friction stir welded aluminum alloys, Trends in Welding Research, Proc.of the Fifth International Conference, ASM International (Pine Mountain, GA), J. Vitek, S. David, J. Johnson, H. Smartt,and T. DebRoy, Ed., Materials Park, OH, 574-579, 1998), June 1-5, 1998.

[83] Y. S. Sato, S. H. C. Park, H. Kokawa, Microstructural factors governing hardness in friction-stir welds of solidsolution-hardened Al alloys, Metall. Mater. Trans. A, 32 (2001) 3033-3042.

[84] M. Kumagai, S. Tanaka, Properties of aluminum wide panels by friction stir welding, First International Symposium on Friction Stir Welding, June 1999 (Thousand Oaks, CA), TWI, 1999.

[85] K. Colligan, I. Ucok, K. McTernan, P. Konkel, J. Pickens, Friction stir welding of thick section 5083-H131 and 2195-T8P4 aluminum plates, Third International Symposium on Friction Stir Welding, TWI, Kobe, Japan, Sept 27-28, 2001.

[86] M. James, D. Hattingh, G. Bradley, Weld Tool Travel Speed Effects on Fatigue Life of Friction Stir Welds in 5083 Aluminum, Int. J. Fatigue, 25 (2003), 1389-1398. DOI: https://doi.org/10.1016/S0142-1123(03)00061-6

[87] C. Juricic, C. Dalle Donne, U. Drebler, Effects of heat treatment on mechanical properties of friction stir welded 6013, Third International Symposium on Friction Stir Welding TWI, Kobe, Japan, Sept 27-28, 2001.

[88] P. Hema, S. M. Gangadhar, K. Ravindranath, Influence of friction stir welding parameters on the micro structural and mechanical properties of aluminum alloy, 6061, Int. J. Appl. Eng. Res., 7 (2012) 907-916.

DOI: https://doi.org/10.1016/j.matdes.2008.09.016
[89] H. Fujii, L. Cui, M. Maeda, K. Nogi, Effect of tool shape on mechanical properties and microstructure of friction stir welded aluminum alloys, Mater. Sci. Eng. A, 419 (2006) 25-31.

DOI: https://doi.org/10.1016/j.msea.2005.11.045

[90] M. Dumont, A. Steuwer, A. Deschamps, M. Peel, P. Withers, Microstructure mapping in friction stir welds of 7449 aluminium alloy using SAXS, Acta Mater., 54 (2006) 4793-4801.

DOI: https://doi.org/10.1016/j.actamat.2006.06.015

[91] M. Cabibbo, H. J. McQueen, E. Evangelista, S. Spigarelli, M. Di Paola, A. Falchero, Hot Deformation and Processing of Aluminum Alloys, Mater. Sci. Eng. A, 460461 (2007) 86-94.

[92] E. O. Hall, The deformation and aging of mild steel III, Discussion and results in Proceedings of The Physical Society, B64 (1951) 747-753.

[93] M. A. Sutton, A. P. Reynolds, D. Q. Wang, C. R. Hubbard, A study of residual stresses and microstructure in 2024-T3 aluminum friction stir butt welds, J. Eng. Mater. Technol., 124 (2002) 215.

DOI: https://doi.org/10.1115/1.1511521

[94] A. Ali, M. W. Brown, C. A. Rodopoulos, S. Gardiner, Characterization of 2024-T351 friction stir welding joints, J. Fail. Anal. Prev., 6 (2006), 83-96.

[95] D. M. Rodrigues, C. Leitão, R. Louro, H. Gouveia, A. Loureiro, High speed friction stir welding of aluminium alloys, Sci. Technol. Weld. Join., 15 (2010) 676-681. DOI:

https://doi.org/10.1179/136217110X12785889550181

[96] A. Tronci, R. McKenzie, R. Leal, D. Rodrigues, Microstructural and mechanical characterisation of 5XXX-H111 friction stir welded tailored blanks, Sci. Technol. Weld. Join., 16 (2011), 433-439.

DOI: https://doi.org/10.1179/1362171811Y.0000000012

[97] K. Elangovan, V. Balasubramanian, Influences of post-weld heat treatment on tensile properties of friction stir-welded AA6061 aluminum alloy joints, Mater. Charact., 59 (2008) 1168-1177.

DOI: https://doi.org/10.1016/j.matchar.2007.09.006 
[98] D. Radaj, Review of fatigue strength assessment of in friction stir welded 2024-T351 aluminium joints, Int. J. nonwelded and welded structures based on local Fatigue, 25 (2003) 77-88. parameters, Int. J. Fatigue, 18 (1996) 153-170.

DOI: https://doi.org/10.1016/0142-1123(95)00117-4

[99] W. Fricke, Fatigue analysis of welded joints: state of development, Mar. Struct., 16 (2003) 185-200.

DOI: https://doi.org/10.1016/S0951-8339(02)00075-8

DOI: https://doi.org/10.1016/S0142-1123(02)00038-5

[100] M. P. Kaplan, T. A. Wolff, I. Willis \& Kaplan, ASM Hand Book Volume 19 Fatigue and Fracture, ASM International, (1996) 557-564,

[101] R. Stephen, A. Fatemi, R. Stephen, H. Fuchs, Metal fatigue in Engineering, John

Wiley \& Son Co, 2001.

[102] S. Maddox, Review of fatigue assessment procedures for welded aluminium structures, Int. J. Fatigue, 25 (2003) 1359-1378.

DOI: https://doi.org/10.1016/S0142-1123(03)00063-X

[103] C. Zhou, X. Yang, G. Luan, Effect of oxide array on the fatigue property of friction stir welds, Scr. Mater., 54 (2006), 1515-1520.

DOI: https://doi.org/10.1016/j.scriptamat.2005.12.036

[104] Health and Safety Executive, Comparison of Fatigue Provisions in Codes and Standards: Vol 2, HSE Books,

http://www.hse.gov.uk/research/otopdf/2001/oto01083.p df, accessed July 2020.

[105] H. Aydin, A. Bayram, M. T. Yildirim, K. Yiğit, Influence of welding parameters on the fatigue behaviours of friction stir welds of 3003-o aluminum alloys, Mater Sci., 16 (2010) 9-12.

[106] T. R. Gurney, Fatigue of Welded Structures, Cambridge University Press, 2nd Edition, 1979.

[107] D. Booth, I. Sinclair, Fatigue of Friction Stir Welded 2024-T351 Aluminium Alloy, Mater. Sci. Forum, 396 (2002), 1671-1676.

DOI: doi.org/10.4028/www.scientific.net/MSF.396402.1671

[108] G. Bussu, P. Irving, The role of residual stress and heat affected zone properties on fatigue crack propagation

[109] G. Patton, C. Rinaldi, Y. Bréchet, G. Lormand, R. Fougères, Study of fatigue damage in 7010 aluminum alloy, Mater. Sci. Eng. A, 254 (1998) 207-218. DOI: https://doi.org/10.1016/S0921-5093(98)00762-X

[110] E. Hornbogen, E. A. Starke, Overview No. 102 Theory assisted design of high strength low alloy aluminum, Acta Metall. Mater., 41 (1993) 1-16. DOI: https://doi.org/10.1016/0956-7151(93)90334-O

[111] A. Merati, G. Eastaugh, Determination of fatigue related discontinuity state of 7000 series of aerospace aluminum alloys, Eng. Fail. Anal., 14 (2007), 673-685. DOI: https://doi.org/10.1016/j.engfailanal.2006.02.016

[112] A. K. Vasudévan, R. D. Doherty, Grain boundary ductile fracture in precipitation hardened aluminum alloys, Acta Metall., 35 (1987) 1193-1219.

DOI: https://doi.org/10.1016/0001-6160(87)90001-0

[113] P. J. Withers, Residual stress. Part 2-Nature and origins, Mater. Sci. Technol., 17 (2001), 366-375.

DOI: https://doi.org/10.1179/026708301101510087

[114] M. N. James, D. J. Hughes, Z. Chen, H. Lombard, D. G. Hattingh, D. Asquith, J. R. Yates, P. J. Webster, Residual stresses and fatigue performance, Eng. Fail. Anal., 14 (2007), 384-395.

DOI: https://doi.org/10.1016/j.engfailanal.2006.02.011

[115] E. Brinksmeier, J. T. Cammett, W. König, P. Leskovar, J. Peters, H. K. Tönshoff, Residual stressesmeasurement and causes in machining processes, CIRP Ann. - Manuf. Technol., 31 (1982), 491-510.

DOI: https://doi.org/10.1016/S0007-8506(07)60172-3

[116] A. Ohta, N. Suzuki, Y. Maeda, K. Hiraoka, T. Nakamura, Superior fatigue crack growth properties in newly developed weld metal, Int. J. Fatigue, 21 (1999) 113-118.

DOI: https://doi.org/10.1016/S0142-1123(99)00062-6

[117] C. M. Chen, R. Kovacevic, Parametric finite element analysis of stress evolution during friction stir 
welding, Proc. Inst. Mech. Eng. Part B J. Eng. Manuf., 220 (2006) 1359-1371.

DOI: https://doi.org/10.1243/09544054JEM324

[118] R. Nandan, G. G. Roy, T. J. Lienert and T. DebRoy, Numerical modelling of 3D plastic flow and heat transfer during friction stir welding of stainless steel, Sci. Technol. Weld. Join., 11 (2006) 526-537.

DOI: https://doi.org/10.1179/174329306X107692

[119] K. Colligan, Welding Journal, 78-7 (2009) 229-237.

[120] H. N. B. Schmidt, T. L. Dickerson and J. H. Hattel, Material flow in butt friction stir welds in AA2024-T3, Acta Mater., 54 (2006), 1199-1209.

DOI: https://doi.org/10.1016/j.actamat.2005.10.052

[121] A. P. Reynolds, Visualisation of material flow in autogenous friction stir welds, Sci. Technol. Weld. Join., 5 (2000) 120-124(5). DOI: https://doi.org/10.1179/136217100101538119

[122] L. Fratini, G. Buffa, D. Palmeri, J. Hua and R. Shivpuri, Material flow in FSW of AA7075-T6 butt joints: numerical simulations and experimental verifications, Sci. Technol. Weld. Join., 11 (2006) 412421(10).

DOI: https://doi.org/10.1179/174329306X113271

[123] A. Norman, T. Brough and P. B. Pragnell, High resolution EBSD analysis of the grain structure in an aa2024 friction stir weld, Mater. Sci. Forum, 331-337 (2000) 1713- $1718 . \quad$ DOI: doi.org/10.4028/www.scientific.net/MSF.331-337.1713

[124] D. P. P. Booth, M. J. Starink and I. Sinclair, Analysis of local microstructure and hardness of $13 \mathrm{~mm}$ gauge 2024-T351 AA friction stir welds. Mater. Sci. Technol., 23 (2007), 276-284.

DOI: https://doi.org/10.1179/174328407X157290

[125] M. Sutton, B. Yang, A. Reynolds and R. Taylor, Microstructural studies of friction stir welds in 2024-T3 aluminum. Mater. Sci. Eng. A, 323 (2002) 160- 166. DOI: https://doi.org/10.1016/S0921-5093(01)01358-2

[126] T. L. Dickerson and J. Przydatek, TWI report 7387.03/98/1024.03, 2000.
[127] Y. H. Zhao, S. B. Lin, F. X. Qu and L. Wu, Influence of pin geometry on material flow in friction stir welding process, Mater. Sci. Technol., 22 (2006), 45-50(6).

DOI: https://doi.org/10.1179/174328406X78424

[128] G. Buffa, J. Hua, R. Shivpuri and L. Fratini, Material Flow in FSW of T-joints: Experimental and Numerical Analysis, Mater. Sci. Eng. A, 419 (2006), 381-388.

[129] H. Schmidt and J. Hattel, A local model for the thermomechanical conditions in friction stir welding, Model. Simul. Mater. Sci. Eng., 13 (2005) 77-93.

[130] M. Guerra, C. Schmidt, J. McClure, L. . Murr and A. Nunes, Flow Patterns During Friction Stir Welding, Mater. Charact., 49 (2002), 95-101.

DOI: https://doi.org/10.1016/S1044-5803(02)00362-5

[131] W. M. Thomas, K. I. Johnson and C. S. Wiesner, Friction Stir Welding - Recent Developments in Tool and Process Technologies, Adv. Eng. Mater., 5 (2003) 485490. DOI: https://doi.org/10.1002/adem.200300355

[132] Y. Murakami, Metal Fatigue- Effects of Small Defects and Nonmetallic Inclusions, Elsevier Ltd, 2002.

[133] M. A. Wahab and M. S. Alam, The significance of weld imperfections and surface peening on fatigue crack propagation life of butt-welded joints, J. Mater. Process. Technol., 153-154 (2004) 931-937.

DOI: https://doi.org/10.1016/j.jmatprotec.2004.04.150

[134] J. Hyzak and I. Bernstein. Effect of defects on the fatigue crack initiation process in two P/M superalloys - 1 .

Fatigue origins. Metall. Mater. Trans. A, 13 (1982) A(1):33-43,.

[135] D. G. Kinchen, L. Martin, M. Space, N. Orleans and E. Aldahir, NDE of Friction Stir Welds in Aerospace Applications,

http://archive.org/details/nasa_techdoc_20020066657, accessed March 2012.

[136] M. H. Ogle, P. L. Threadgill and S. J. Maddox, Joints in Aluminium - Inalco '98: Seventh International Conference, Woodhead Publishing, 1999. 


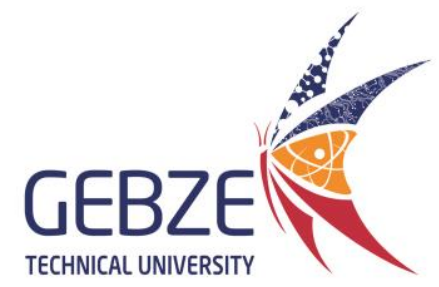

Acta Materialia Turcica

Volume 4, October 2020, Pages 1-39

[137] A. Leonard and S. Lockyer, Flaws in friction stir http://www.innovaltec.com/downloads/rowe_matcong.pd welds, 4th International Symposium on friction stir f, accessed May 2012.

Welding, Park City Utah, USA, May 14-16, 2003.

[138] M. M. Attallah and H. G. Salem, Friction stir welding parameters: a tool for controlling abnormal grain growth during subsequent heat treatment, Mater. Sci. Eng. A, 391 (2005) 51-59.

DOI: https://doi.org/10.1016/j.msea.2004.08.059

[139] H. Okamura, K. Aota, M. Sakamoto, M. Ezumi, K. Ikeuchi, Behaviour of oxides during friction stir welding of aluminium alloy and their effect on its mechanical properties, Weld. Int., 16 (2002) 266- 275.

DOI: https://doi.org/10.1080/09507110209549530

[140] Y. S. Sato, F. Yamashita, Y. Sugiura, S. H. C. Park and H. Kokawa, FIB-assisted TEM study of an oxide array in the root of a friction stir welded aluminium alloy, Scr. Mater., 50, (2004) 365-369.

DOI: https://doi.org/10.1016/j.scriptamat.2003.10.008

[141] H. S. Park, T. Kimura, T. Murakami, Y. Nagano, K. Nakata and M. Ushio, Microstructures and mechanical properties of friction stir welds of $60 \% \mathrm{Cu}$ $40 \%$ Zn copper alloy. Mater. Sci. Eng. A, 371 (2004) 160169. DOI: https://doi.org/10.1016/j.msea.2003.11.030

[142] A. O'Brien, Welding Hand Book: Welding Processes, Part 2 Volume 3 Ninth Edition, Miami, Americal Welding Society, 2007.

[143] D. G. Hattingh, MNNU Seminar, 2012.

[144] M. Peel, A. Steuwer, M. Preuss and P. J. Withers, Microstructure, Mechanical Properties and Residual Stresses as a Function of Welding Speed in Aluminum AA5083 Friction Stir Welds, Acta Mater., 51 (2003) 4791-4801.

DOI: https://doi.org/10.1016/S1359-6454(03)00319-7

[145] R. Nandan, T. Debroy, H. Bhadeshia, Recent advances in friction-stir welding - Process, weldment structure and properties, Prog. in Mat. Sci., 53 (2008), 980-1023.

DOI: https://doi.org/10.1016/j.pmatsci.2008.05.001

[146] C. E. D. Rowe and W. Thomas, Advances in tooling materials for friction, 